\title{
ESTABLISHING AND UNDERSTANDING OF GROUP DYNAMICS AND PROCESS WITHIN SINGLE-SESSION MUSIC THERAPY GROUPS OPEN TO BOTH ADOLESCENTS WITH MENTAL ILLNESS AND MENTAL \\ HEALTH STAFF.
}

\author{
BY \\ ERIN BETH UPJOHN BEATSON
}

\begin{abstract}
An exegesis
submitted to the New Zealand School of Music

in partial fulfilment of the requirements for the degree of

Master of Music Therapy

New Zealand School of Music
\end{abstract}

(2012) 


\section{ABSTRACT}

The purpose of this research was to gain an understanding of group dynamics and process within single-session music therapy groups open to both adolescents and mental health staff. The study investigated factors that influenced group dynamics; how existing understandings of group process were evidenced within the sessions and how the groups could best be facilitated. A qualitative, exploratory method was used. Secondary analysis of clinical data from seven group music therapy sessions was carried out. A process of thematic analysis was applied to the narrative data and recordings of group improvisations were analysed using an adapted version of the Music Therapy Group Improvisation Analysis Model (MTGI-AM). It was found that developmental group process was evident within single sessions of music therapy. For example, a process of moving from disconnection, to establishing common ground, developing musical cohesion, then taking risks and negotiating closure, was audible within group improvisations. Group dynamics were affected by the physical environment and wider institutional contexts; by the leadership styles and structures implemented; the contributions of group members; the quality of existing and emerging connections between individuals; and aspects of the individuals themselves. The structure of music provided stability, mediated energy levels and presented opportunities for individuals to develop leadership and autonomy. Groups became more autonomous and took more risks as musical and interpersonal cohesion was established. 
Thank you to my research supervisor, Daphne Rickson, for her never-ending patience and belief.

Thank you to my partner Quinn Wilkins for backing me on both good and bad days, for enduring my roller-coaster study-monster moods and for providing many cups of tea at times of stress.

Thank you to my family for their interest and support, and for all the time and resources they have given me that have made this possible. Thank you to Mum for phone calls and emails that broke my social hibernation.

Thank you to Beaulah Pragg, for her writing prowess and friendship.

Thank you to my classmates for their insights and motivation.

Thank you to the staff and young people at the unit. I have learned so much from you. I have a lot of special memories. 


\section{CONTENTS}

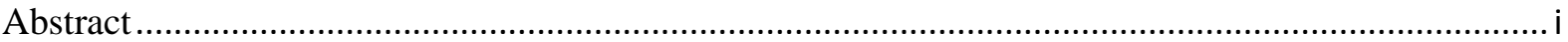

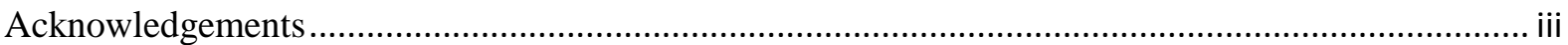

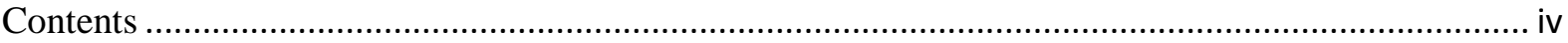

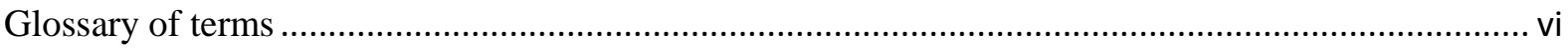

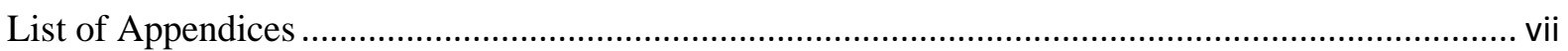

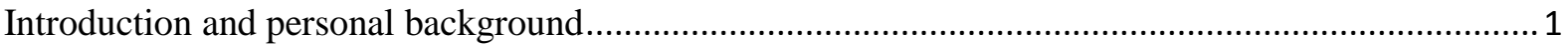

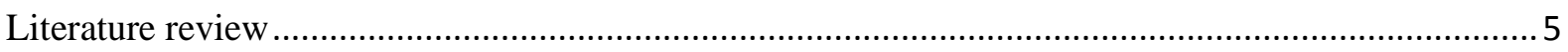

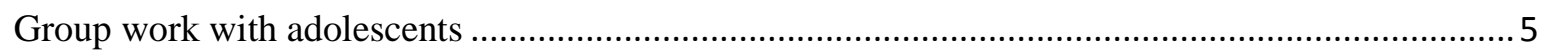

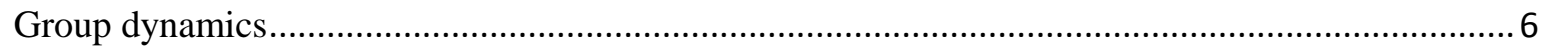

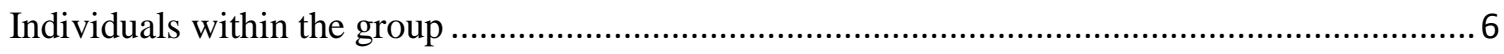

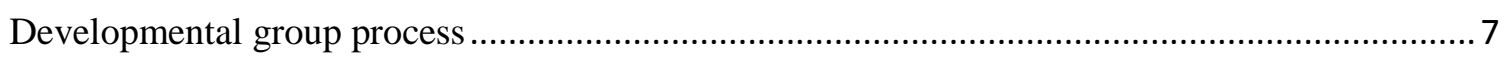

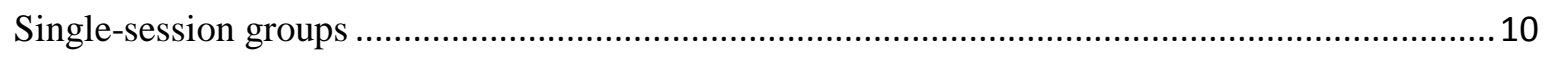

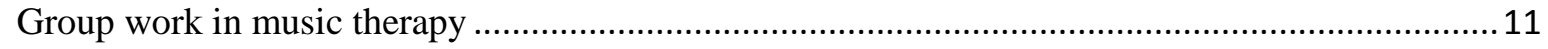

Groups and Process in music therapy with adolescents ........................................................... 12

Group dynamics in improvisational music therapy .................................................................. 15

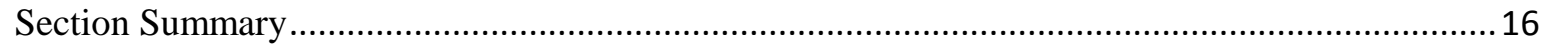

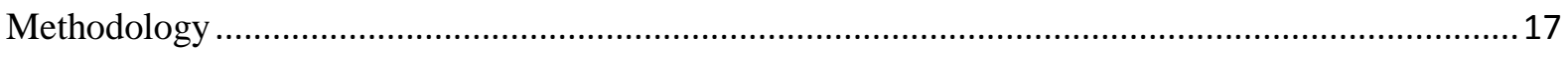

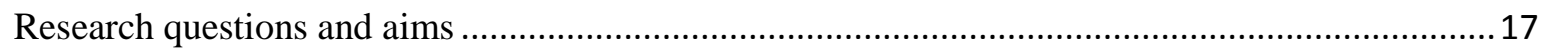

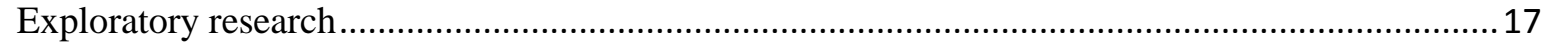

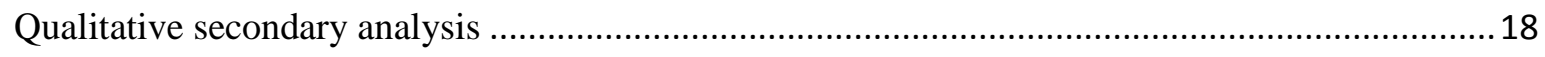

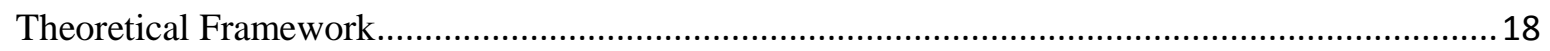

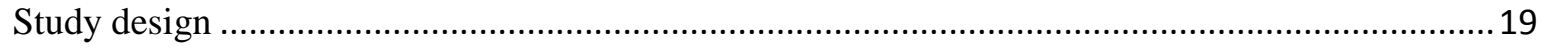

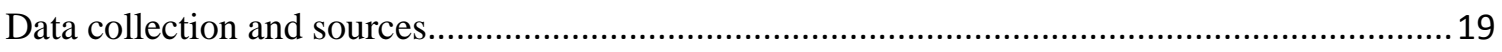

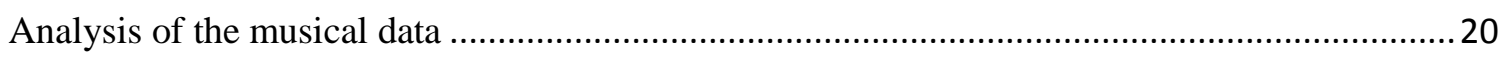

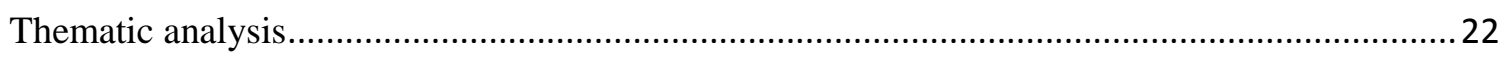

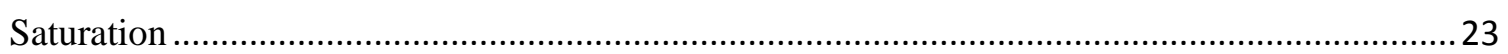

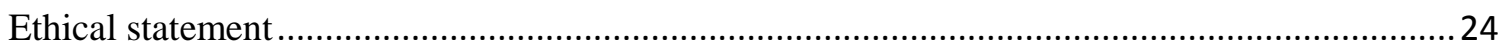

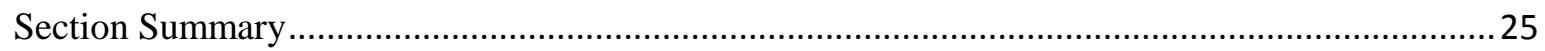


Findings

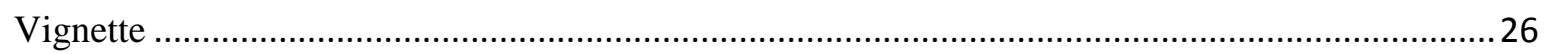

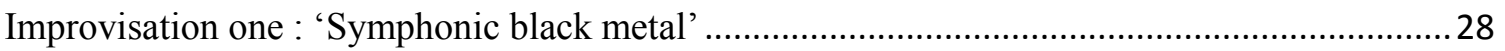

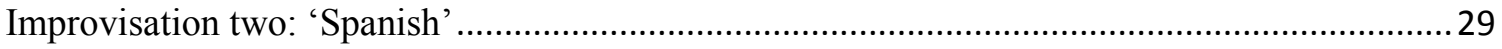

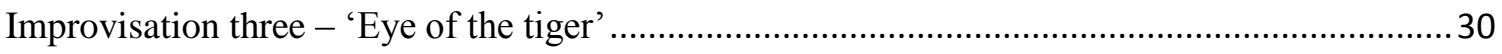

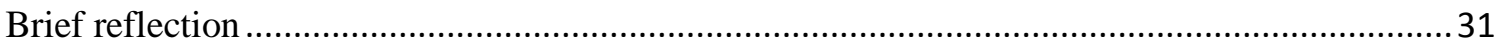

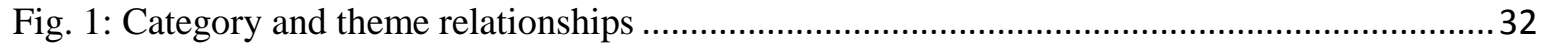

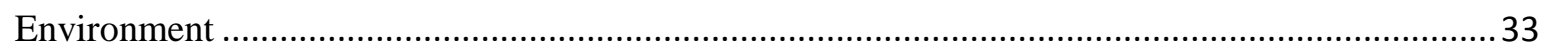

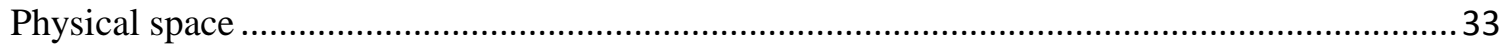

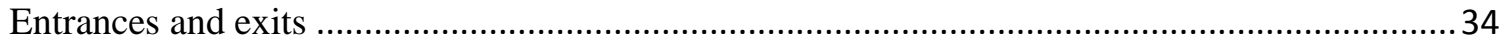

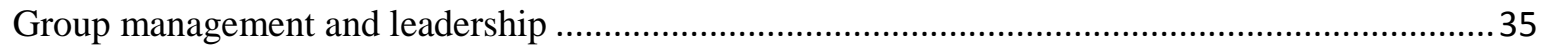

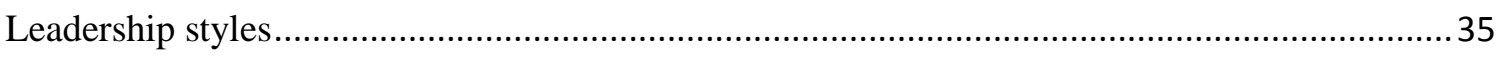

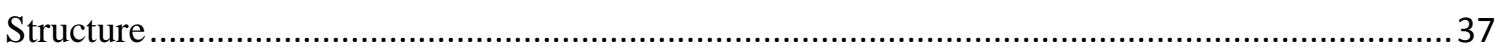

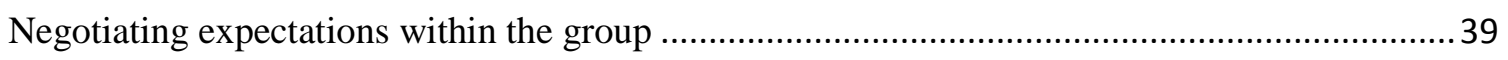

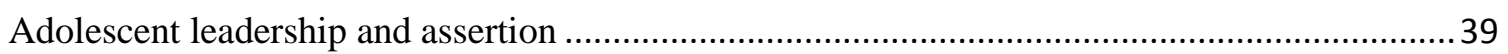

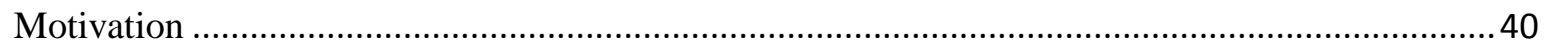

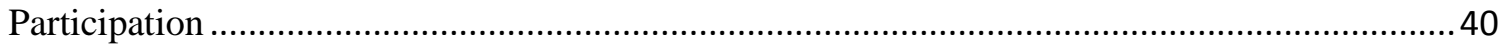

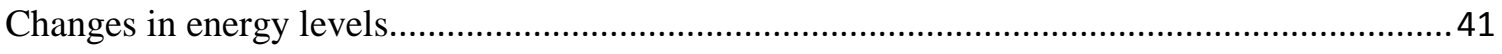

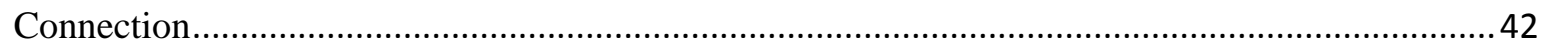

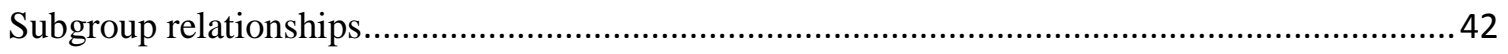

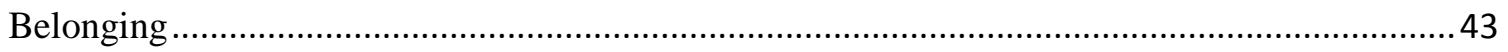

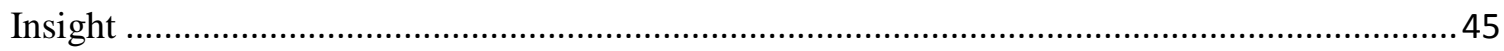

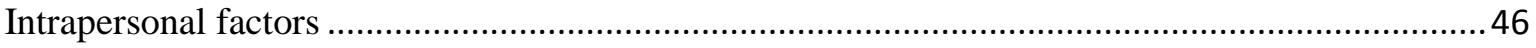

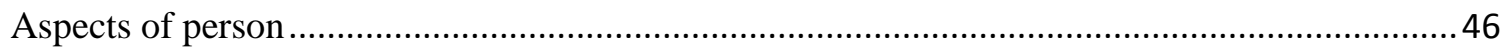

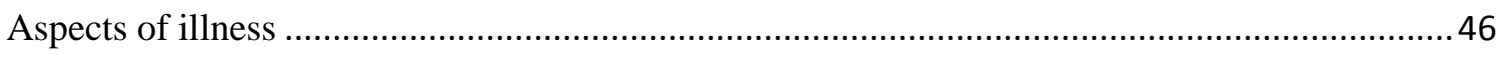

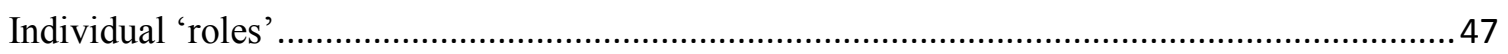

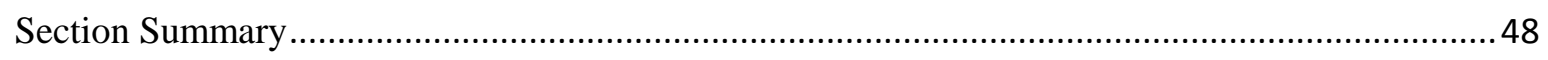

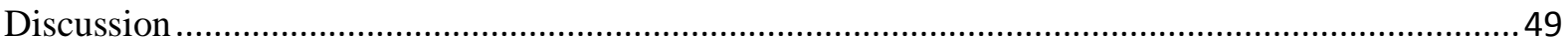

Fig. 2: Group process theory and music analysis ........................................................................ 50

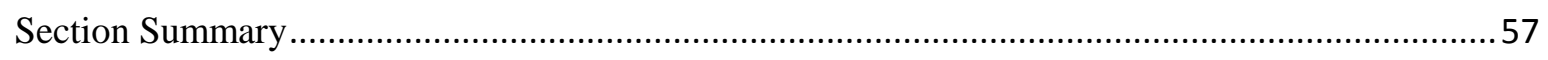

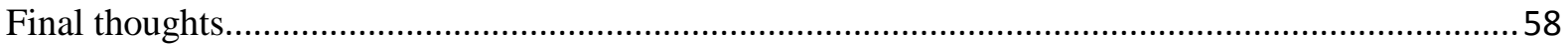

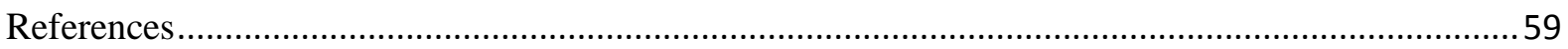


Anhedonia - the loss of the ability to gain pleasure from normally pleasurable experiences.

Avolition - lack of initiative, motivation and goal-directed behaviour.

Crescendo - gradual increase in volume of a musical passage

Decrescendo - gradual decrease in volume of a musical passage

Giant Weta - native New Zealand insect. There are many species of weta, 11 of which are called 'giant weta'.

'Jam' - informal term for improvisation or improvise.

Kalimba - an African musical instrument made of a wooden box and metal bars of various lengths that are plucked by the fingers or thumbs.

Kaupapa Maori - Frameworks and principles that are indigenous to Maori.

Maraca - A Latin-American instrument made of a hollow gourd rattle, filled with pebbles or beans.

'Noodling' - informal term for playing around and exploring instrumental sounds.

Paranoia - an extreme and irrational distrust of others.

Tangata Whai Ora - people seeking wellness

Whanau - broad term for family, including extended family and close friends. Who is 'whanau' is defined by the individual.

Whanaungatanga - strength of relationships and interconnection. Similar to kinship, connecting as one people. 


\section{LIST OF APPENDICES}

Appendices. 65

Appendix one: Example of Improvisation analysis. .65

Appendix two: Starting points for thematic analysis 73

Appendix three: Examples of coding process ……….............................................. 74

Appendix four: Information sheets and consent forms................................................. 76

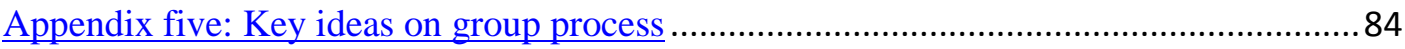

Appendix six: Recommendations to group leaders …….............................................. 86 


\section{INTRODUCTION AND PERSONAL BACKGROUND}

My interest in this topic has arisen from my initial experiences in a clinical placement on an acute adolescent mental health inpatient unit. This unit runs a 'Therapeutic Day Programme' (TDP) five days a week, which consists of a variety of activity groups aiming to address the diverse needs of the adolescents admitted to the unit. The groups have a mix of cultural, cognitive, recreational and activity-based focuses. At any one time there can be up to 13 adolescent inpatients on the unit and up to another eight outpatients who only attend the TDP.

There is a strong culture of expectation that adolescents attend the day programme, but in reality it is attended in a very open way, with some adolescents making a firm choice not to attend and others too unwell to take part at all, or able to take part in just some of each session. In addition, the young people on the unit are often required to attend a number of appointments and meetings throughout the day and these often clash with the group activities of the TDP.

The day programme is also attended by mental health staff, most notably occupational therapists, nurses and mental health support workers. Usually, one or two staff members will have the role of group facilitators and any other staff present will participate in the group at a similar level to that expected of the adolescent members.

TDP attendance by a variety of staff is useful in several ways. Firstly, this may reduce barriers between the adolescent inpatients and mental health staff. As a bi-cultural unit which incorporates both Kaupapa Maori frameworks and mainstream clinical models of intervention, the concept of 'whanaungatanga' is important. Whanaungatanga can be loosely translated as the strength of relationships between people. The term normally applies to an extended family, but in the bi-cultural context of the ward, the whole ward community is considered whanau. Attending and participating in TDP offers staff an opportunity to 'get to know' the adolescents and form strong relationships, which contribute to whanaungatanga. From a mainstream clinical approach, group activities are also an ideal place for staff to make observations of the adolescents' mood, concentration and engagement with others.

Some element of continuity is provided by keeping the weekly roster constant. For example, my music therapy group took place at 9:30am each Tuesday morning. However, the very open nature of Therapeutic Day Programme groups, combined with changeability of 
inpatients (new admissions and discharges from day to day) and staff rosters, meant that each group session has a different combination of members. Some may be familiar with the activities, the facilitator and other members, while for others the group may be completely new.

Group sessions with changing memberships are not uncommon in this area of music therapy. For example, Leslie Bunt describes similar open-group music therapy work in a psychiatric setting. He states that within this context, each group can be considered a one-off experience in its own right (Bunt, 1994). Because the groups were very rarely if ever comprised of the same members, I have chosen to refer to them as single sessions. Another possible conceptualisation of them is as 'fast-open' groups. Slow-open groups are often referred to in psychotherapy literature (Blackwell, 2011; Foulkes, 1983; Yalom, 1995). Individuals remain in these groups for long periods of time, but group membership does change. The term 'fastopen' could suggest a much faster turnover of group members.

The group can be a powerful tool for therapeutic work with adolescents (Aigen, 1997; Goodman, 2007; Henderson, 1983; Hendricks, 2001; Hibben, 1991; Kim, et al., 2006; Malekoff, 2004; McFerran-Skewes, 2000; McFerran \& Wigram, 2005; Montello \& Coons, 1998; Nicoll, 2008; Pavlicevic, 2003; Sandness, 1991; Thygesen, 2008; Ulrich, Houtmans, \& Gold, 2007). However, little has been written about single session groups and the participation of well adults adds another dimension to the task of group facilitation.

As a student music therapist, I found the one-off nature of the groups challenging. I found it difficult to plan for a group which was unknown to me and flexibility was always required. To make sense of the complexity of the groups and manage my sense of being overwhelmed, I often focused on specific individuals' reactions. As a result, I felt I may be missing a bigger picture of what was happening for the whole group. I wondered what could realistically be achieved within each session and whether the group members would come to trust each other enough to gain something meaningful.

Despite these concerns, I held a profound faith in the vehicle of 'the group'. I have been fortunate enough to be part of several long-term groups which for me felt cohesive, trusting and supportive. These have included a high school drama class, the cast of an undergraduate level dramatic production, a volunteer group that provides phone counselling aimed at adolescents and the master's level music therapy class. Three out of four of these groups have 
been creative in nature and so my experience has led me to a belief in creative pursuits as an effective way to form a cohesive group.

During my involvement in the undergraduate level dramatic production, I experienced an episode of major depression. At this time I often found it difficult to attend rehearsals, but each time I did attend I found the group experience helpful. On reflection, I feel this group helped to 'bring me out of myself' and become more aware of others, thus shifting my focus and reducing my sense of isolation. Having a valued role to play in the group was important for my sense of self-worth. In addition, the group provided me with opportunities to support and be supported by others, and many of the group's activities were effective in raising my energy levels. Although the focus of this group was not therapeutic, my involvement in it was therapeutic for me and this experience has given me a strong belief in the value of groups for those experiencing depression.

The groups in my life that I have mentioned as cohesive, trusting, supportive and therapeutic have all met together long-term, for between two months to two years. However, I also hold the belief that short-term, transient connections between people can be valuable to a person's growth. While travelling overseas I made a lot of connections with people that I still value, even though for the most part we have not kept in touch. I also felt an extra license to act and react 'in-the-moment', when in an overseas environment which wasn't weighed by the more enduring contexts and relationships of my life. I feel these 'in-the-moment' experiences and connections were integral to my personal growth.

In the context of the hospital, which is separate to the adolescent's usual arenas of life (family, school, friendships, sometimes city), I felt it was possible they would experience greater freedom in their ability to react in the moment, as I had. However, I was also aware it was possible and perhaps more likely that the unfamiliarity would cause anxiety and inhibition. If anxiety could be eased within the group and the group members brought to an awareness of the moment, I felt that meaningful experiences could be had and connections made in even a single session of music therapy. In summary, my travelling experiences lent me the hope that connections made between group members and experiences had in-themoment', in even a single session of music therapy, could affect a person's life positively.

It is from this background that my interest in group process and dynamics within single music therapy sessions has developed. My research has aimed to inform my practice by giving me a 
fuller picture of what was happening for the 'whole group' within each session. I hoped that this understanding would enable me to facilitate these groups more effectively, potentially leading to valuable outcomes for group members.

In addition to the learning and application for my own clinical practice, I hope that the ideas I am able to draw out about group processes and dynamics resonate with and are useful to other music therapists who work in changeable settings. Perhaps some elements of this research will be relevant beyond music therapy, in, for example, group psychotherapy and other interventions or activities involving open or one-off groups. 


\section{LITERATURE REVIEW}

Literature from areas relevant to combined themes of group dynamics, process and the particular circumstance of single-session group work; adolescents; and music therapy will be reviewed and summarised.

\section{GROUP WORK WITH ADOLESCENTS}

For several reasons, group work is especially relevant to adolescents.

The web of relationships in an adolescent's life can be complex, including family, friends, schools, teachers, workplaces, boyfriends or girlfriends and others. Groups seem a natural setting for adolescents, who are typically forming and re-forming their own social 'webs'.

Adolescents are often more trusting of peers than of adults. Considering that most social learning is thought to take place by observing others and the results of their actions (Bandura $\&$ Walters, 1983), a group setting which includes others their own age is an appropriate place for adolescents to develop and hone interpersonal skills.

Group therapy can also offer some experiences that one-on-one therapy cannot. For example, groups offer greater opportunities for cooperation and for comparing one's own ideas or behaviours to others' (Wood, 2009).

The psychological theorist Erikson (1980) describes adolescents as facing three major challenges in social development. The first is that of separation and individuation from structures such as family, so that the person can be autonomous. The second is that of forming an identity, versus identity confusion; and the third is that of forming a capacity for and balance between, intimacy and isolation. All three of these challenges could be aided by group experiences (Malekoff, 2004). In groups, an adolescent may encounter new viewpoints and behaviours not previously experienced by the adolescent. A 'safe' group can be a place to consider, test and try out some of these newfound ways of being and so help the adolescent begin to develop autonomy. Group membership and role within a group can be a strong aspect of identity formation. Groups can also be a powerful place to experience a sense of 'togetherness' and to develop trust, which could assist a capacity for intimacy. 


\section{GROUP DYNAMICS}

The French social psychologist Gustave Le Bon was the founder of group psychology with his study "The crowd: A study of the Popular Mind" in 1897. Further theories of group behaviour and group dynamics have been developed by a great number of psychologists over time including Freud, Lewin and Bion (Erford, 2010). These theories of group behaviour and dynamics have been applied widely in education, work, recreation and other settings, but there is also research and theory based specifically on group psychotherapy. Yalom has been influential in this area and his book "The Theory and Practice of Group Psychotherapy" (1995) has become the classic text on this subject.

Yalom outlined therapeutic factors that contribute to positive outcomes in group therapy; derived from extensive research involving self-report from clients. Corder, Whiteside \& Hazlip (1981) extended this research to determine which of Yalom's factors were most helpful to adolescents. They found some uniqueness for the adolescent groups. Of Yalom's twelve therapeutic factors, the five thought by Corder, Whiteside and Hazlip (1981) to be most helpful to adolescents are outlined below.

- Catharsis involves the release of emotional tension. This can be achieved through free and uninhibited expression of emotion.

- Existential factors refer to recognising shared features of existence, such as having ultimate responsibility for our own actions.

- Interpersonal learning involves receiving feedback from others and experimenting with new ways of relating.

- Group cohesiveness develops when all members feel a sense of belonging, acceptance and validation. Humans have an instinctive need to belong.

- Universality is demonstrated when group members realise they may not be alone in their experiences and concerns. This can help combat isolation.

\section{INDIVIDUALS WITHIN THE GROUP}

Any group is made up of a number of individuals and each individual makes a unique contribution to the flavour of the group as a whole. Salient characteristics of individuals such 
as their culture, gender, age, status with peers, confidence and whether they have additional needs can impact significantly on the group (Westergaard, 2009). If there is a sharp distinction between group members in one or more such characteristics, it may divide group members or become a focal point of the group. Westergaard gives an example from her own clinical practise, working with a group of adolescents, one of whom identified as lesbian. Aggression directed towards the young woman by another group member forced the group to focus on themes of sexuality and resolve their conflict by coming to an acceptance of diversity.

Another way of conceptualising the impact of individuals on the whole group is that of social roles played out by each group member (Vernelle, 1994, cited in Westergaard, 2009). Examples of some such roles are the 'monopoliser', the 'good listener', or the 'silent critic'. These may be roles that the group members typically fall into in other areas of their lives and the group can be an effective vehicle to help individuals recognise and address this when it is an issue. Roles can be either disruptive or helpful to the needs of other group members.

\section{DEVELOPMENTAL GROUP PROCESS}

Throughout the last century, many theorists have recognised and described distinctive developmental stages that groups go through (Brabender \& Fallon, 2009). There appear to be more similarities than differences between the various models of group development. Each seems to articulate a process of first coming to know the boundaries of the group, then testing these boundaries, before growing in trust and acceptance of others in the group, which leads to a sense of cohesion and the group being able to work effectively to achieve its goals and finally to a period of closure, negotiating and dealing with the loss of the group as it comes to its end (Wheelan, 2005).

One of the most commonly cited models of group development calls these stages forming, storming, norming, performing and adjourning (Tuckman \& Jensen, 1977). This model was developed after reviewing more than fifty previous models of group development and synthesising their commonalities. These theorists recognise there are instances when groups do not strictly adhere to the exact sequence. For example, although the 'storming' phase diminishes, they note that aspects of it may still be present in each subsequent phase. 
The idea that storming can be an element that continues throughout the developmental group process is partially echoed by Nitsun (1991), in his concept of the anti-group. Nitsun used this concept to draw emphasis to group destructive processes, which were not given much recognition in the Foulkesian tradition of psychotherapy in which he was trained (Motherwell \& Shay, 2005). The anti-group represents aggression within and toward the group that is destructive to the therapeutic task. It can have latent and manifest properties and can occur at all levels of the group: individual, sub-group, whole-group and external to the group. The process varies considerably and while in some groups it hardly exists, in others the whole group may be charged with negativity. Rather than focussing on this negativity however, Nitsun says "If the negative and potentially destructive aspects of groups can be recognised, understood and managed, the group is freed up to get on with the creative and collaborative work" (2011, p. 121).

One way the anti-group may manifest on an individual level, is when a person avoids engaging closely with others due to negative attachment representations (Pearce, 2009). Someone who has not developed secure attachment from a young age might have learned to habitually mistrust others, have low expectations of their own deservedness and show a lack of empathy. Gilbert, McEwan, Matos \& Rivis (2011) found that non-secure attachment styles were strongly linked to fears of compassion from others and for oneself. For some participants there was also a link to fear of compassion for others. When affiliative emotions trigger fear, this could make it difficult for the person to engage in group therapy.

One other group life-cycle, by Dies (1996) is outlined below. This particular group life cycle has been chosen because it was developed specifically for adolescent groups in verbal therapy. In this theory, little emphasis is drawn to destructive possibilities within the group. 'Testing of limits' is reframed as a test for the therapist, to ascertain whether s/he will remain open to the adolescent.

The first stage in Dies' (1996) life cycle of an adolescent group is that of initial relatedness. Issues of expectations of what is to be done and achieved are addressed. It is important that a positive and safe environment is created.

The second stage is testing of limits. Adolescents explore aspects of their own identity and the therapists and group's reactions to them. The adolescent may try to test whether the therapist 
will remain available to them or whether they will fall into negative patterns towards them that other authority figures in their lives may have.

The third stage is resolving authority issues. This occurs after the group has accepted the therapists' openness to their concerns or expressions of anger and frustration. Trust in the group and the therapist is maintained by accepting self-assertions without penalty.

The fourth stage is work on the self. Therapists can decrease their level of participation and increase the level of responsibility the group has over itself. Interaction between group members increases. Adolescents are often more comfortable learning from one another than from adults, so it is during this stage that the major group work is achieved.

The final stage is moving-on. This involves consolidation of learning and recognition of feelings of loss from ending the group members' time together. The therapist has a more active role again in this stage.

There is little clarity in the literature about whether all groups necessarily move through every developmental stage (McGrath and Tschan, 2004), although McGrath suggests that groups may go through an idiosyncratic process, to reach a similar end point (McGrath, 1991). This matches Nitsun's notion that the group process can vary markedly for different groups.

Other pertinent questions that are yet to be fully answered in the study of group development over time are:

- Do groups of different types change in different or similar ways? (McGrath \& Tschan, 2004)

- If a group follows a different developmental trajectory, is this a sign of dysfunction in the group? (ibid.)

- How do factors external to the group impact on the pattern of stages it goes through? (ibid.)

- What are the mechanisms of change that trigger a shift for a group along this developmental trajectory? (Tuckman \& Jensen 1977). 


\section{SINGLE-SESSION GROUPS}

Yalom (1995) has written specifically about facilitating groups in an acute psychiatric ward. Acute wards have a focus of managing crisis through short-term stays, so the potential of therapy is limited by the available time. The person will likely benefit from ongoing therapeutic engagement in the community, so one appropriate goal of therapy is to engage inpatients in a therapeutic process they will wish to continue after discharge. Other appropriate focuses are to relieve anxiety related to their hospitalisation and to decrease isolation. When less isolated, patients are better able to make use of the ward's therapy resources and to form helpful relationships with others. Improved communication skills may also benefit individuals outside the hospital setting.

Yalom (1995) emphasises it is essential that the focus of inpatient groups be on the here-andnow. There are normally very complex circumstances that have led to a person's hospitalisation and it is not possible to address these issues effectively in a short-term group. A here-and-now focus can help group members to communicate more clearly, to form friendships and to give and receive support from each other.

Yalom also states "too much or too little structuring is detrimental to growth" (1995, p.472). He urges therapists to strive for groups that are as autonomous as possible. However, he recognizes that many inpatients are confused, disorganised, frightened and crave external stability. Providing structure and clear expectations may relieve anxiety. Therapist confidence, clear boundaries of time and place for therapy and a consistent procedure for sessions are all forms of structure that may be helpful.

The importance of structure in single-session format groups is developed by Manor (2010). To illustrate the structure he feels most appropriate, he presents a metaphor of a 'systemic container' that is deepest in the middle and shallow at either end. Activities which are relatively uncomplicated and do not challenge group members should be used to begin a session, allowing individuals to move into their new role as an active member of the group. More challenging activities and deeper feelings or issues can be explored in the middle of a session. A cooling-down period is necessary to prepare members for leaving the group and facing the often chaotic and difficult dynamics of the ward. This model is similar to a scheme from psychodrama involving the sequence of warm-up, then action, then integration (Manor 
\& Dumbleton, 1993, cited in Manor, 2010). The most complex and cathartic activity is the 'action', when the psychodrama is enacted.

Manor (2010) also stresses the need for the experience of the single-session therapy group to be "unprovocative, containing, safe and nourishing" (p. 147). He suggests this can be achieved by adopting a reassuring and undemanding approach to group members and a level of connection that is not too intense. MacKenzie says these groups are "continually rebeginning and working to consolidate into some sense of groupness" (1997, p. 342, cited in Manor, 2010, pg.133).

Recently, two papers exploring the dynamics and facilitation of open groups have been published (Turner, 2011; Blackwell, 2011). These support the ideas of Yalom and Manor, emphasizing the need for group safety and a balance between structure and freedom, with the most structure provided at the beginning of a session. Group leaders need to be able to shift flexibly between more and less active direction and should begin by addressing the purpose and expectations for the session. After quickly fostering cohesiveness, less active facilitation is recommended through the middle of a session in order to empower group members (Turner, 2011). Space should be made for reflection at the end, with awareness that members may be in the group for the last time.

Open groups need to maintain a low level of tension and foster acceptance (Blackwell, 2011). There is little time to repair individual relationships or the overall group dynamic, so conflict should be avoided where possible and any anger directed onto the group leader, who is in a better position to deal with it. Some issues may be too deep to address in an open group, particularly at the beginning or end of a session. Practitioners may wish to consider acknowledging an issue but leaving it for a more appropriate time (Turner, 2011) and discouraging intimacy in the group that could make separation more difficult (Blackwell, 2011).

\section{GROUP WORK IN MUSIC THERAPY}

Group work in music therapy has been described and explored by many authors including Towse (1997), Woodcock (1987), Stewart (1996) and Odell-Miller (2002). These writings focus on group work over time, or in the case of Stewart on a single session experienced by a group that met over time. They nevertheless present some important concepts relevant to all 
groups in music therapy. Many of these have been captured in the more recent writings of McFerran \& Wigram (2007) in an article that combined information from several interviews with music therapists who are leaders in the field of group music therapy. This article discussed the uniqueness of music therapy as a form of group therapy. Some key points are outlined here.

"Music is different to words" (ibid. p. 5). While words express things precisely and unambiguously, music can begin to express things that are not yet fully formulated. Music can also help express amorphous feelings that are difficult to put into words, or which a person does not have a vocabulary for or cognitive understanding of. Using music, many people can 'speak' together at the same time.

"Music can be safer than words" (ibid.). Music can offer safety by avoiding the particularised expression that words require. Music offers a way to non-specifically express feelings that might be risky to verbalise. For example, verbally expressing feelings of anxiety might carry the risk of being kept in hospital for longer.

Music can be spontaneous (ibid.). It is created moment to moment and can bring people into an awareness of the present. Spontaneity also creates opportunities for group members to be surprised by what they do. Being surprised indicates that something has happened differently to what was expected. This experience can help people to be open to a variety of outcomes and therefore bring about change.

"Music creates an interactive entity" (ibid., p.7). The creation of the group's music is shared. This involves interacting and participating. Sometimes the group's music can be experienced as more satisfying than what each person could create alone and this gives each group member the experience of being a part of something bigger than himself or herself.

\section{GROUPS AND PROCESS IN MUSIC THERAPY WITH ADOLESCENTS}

An emphasis on interpersonal communication and learning to work together as a group and reflecting on one's own role within the group has the potential to be helpful in music therapy with adolescents (Plener, Sukale, Ludolph \& Stegemann, 2010). Their study combined music therapy and dialectical behavioural therapy (DBT) approaches in a program for five adolescent girls who engaged in non-suicidal self harm. Music therapy focused on understanding group dynamics and fostering cohesion, while interpersonal issues that 
surfaced were processed in individual DBT sessions. By the end of the program, four of the five girls had stopped injuring.

Rickson (2004) compared instructional and improvisational approaches to music therapy work with adolescent boys with ADHD. One group (C) began music therapy with an instructional approach and by the third session were showing support for each other. Over eight instructional-oriented sessions they further developed enthusiasm, creativity, selfcontrol and pride in what they had mastered. A move to improvisational methods was immediately successful due to their confidence. Their music was communicative and expressive. Through improvisations they were able to further develop interpersonal connections.

A second group (B) had a more uncertain beginning using an improvisational approach (Rickson, 2004). They appeared anxious, looking for more support and direction. It took time for them to develop the skills to play together as a group rather than egocentrically. Moving to an instructional method after eight sessions brought up further anxiety and although they were able to develop self-control and cooperation, they didn't show the same musicalemotional connection as group C. Group B had higher over-all traits of ADHD and this could have affected what they were able to achieve. However, group C's process of moving from an instructional to an improvisational approach matches with the ideal of beginning with clear structure to ease anxiety, then moving to a less directive approach to empower group members (Turner, 2011). This may also have contributed to their success.

A number of researchers have proposed indigenous models of music therapy group development (Achenbach 1997; Bruscia 1987; James and Freed 1989; Morgenstern 1982; Plach 1996; cited in McFerran 2010). These were amalgamated into a Symphonic framework (Skewes, 2001; cited in McFerran 2010). Symphonic form is thought to have similarities with patterns of organic growth (Howat 1983; cited in McFerran 2010); the analogy suggests that group development through the stages outlined in this framework is both natural and ideal.

The first of these stages, the introduction, is characterized by a high level of structure, the development of rules and clarification of expectations (McFerran 2010). During the next stage of exposition, the group may begin to play spontaneously and to explore musical possibilities, while still frequently playing together in time. Trust and support begins to be established in the group. The development stage involves conflict and confrontation of issues. 
Musically, the group may take risks, playing with harmonic dissonance and a number of different 'beats' concurrently. They may even refuse to play together. As issues are resolved, the group moves into a recapitulation stage. There is acceptance of differences between group members and individuals may openly express intense emotions. There is flexibility and freedom in musical style and the group is able to play communicatively, listening to others. The coda stage involves closure, with the group achieving independence from the leader.

In her work with adolescents, McFerran describes four main therapeutic intentions. These are: "fostering understanding, offering acceptance, facilitating development and encouraging participation" (2010, p.55). For those therapists who are focused on understanding or acceptance, she highlights the need to cope with changing group dynamics and handle the intensity of interactions. For those more focused on development or participation, she notes it may be necessary to manage the conflict of the 'development' phase more closely, perhaps by offering a particular goal for the group to work towards.

Several case vignettes are drawn from McFerran's clinical practice with adolescents (2010, some of which involve one-off groups or groups with changeable membership. She highlights key points which may provide guidance for other practitioners such as: group cohesion may not be the best sign of an open group's success, especially with members who are experiencing psychosis; every session should reach a point of closure; some adolescents are more comfortable with 'chaos' than with structure; and a group can dynamically reflect the lives of its members (ibid.). McFerran recommends that clear directions and direct questions are useful when facilitating and notes that adolescents may be unsettled by long silences (ibid.).

Aigen (1997) has given a detailed account of the process experienced over a year by a group of developmentally disabled adolescents in music therapy. The co-facilitators initially retained firm control over the group and its activities, but moved to a more spontaneous way of working which allowed room for expressing feelings. This new style of leadership gave greater control to the group members by responding to their contributions in the moment as well as offering them choice and opportunities to lead. Aigen links the shift in leadership style to a shift in group dynamic, but refrains from labeling which aspect was cause and which effect. He writes at length about how the group's dynamics and alliances were played out physically, through touch and positioning. As the group moved through a period of significant conflict, members used physical contact most prominently to show aggression and 
to provoke others. The group experienced that they could express and survive conflict, anger and aggression and in resolving these issues they began to develop cohesion. This was apparent in their ability to play differentiated musical roles which contributed to a greater whole and in their awareness of others such as who was present or absent for a session. As cohesion developed, physical contact was used more for showing affection and support.

When the group finished for the year, one of the ways members dealt with termination was to distance themselves from each other. This happened expressively through music, gesture and verbal language. Group members were driven to opposite corners of the room by one individual's loud drumming and some unsupportive and hurtful comments were made about each other.

\section{GROUP DYNAMICS IN IMPROVISATIONAL MUSIC THERAPY}

Musical improvisation is an expression of identity (Sansom, 2007) and group improvisations reflect both the group as a whole and the individuals within it.

The sounds of adolescent group improvisations in particular can be "unbridled and chaotic" (McFerran-Skewes, 2003). This may relate to their developmental stage. Teenagers have a desperate need to belong, but also to be an individual (Malekoff, 2004). Fulfilling both these needs requires independence alongside co-ordinated groupness and in music this anomaly might sound strange (McFerran-Skewes, 2003).

McFerran \& Wigram (2007) state that improvisational music can reflect group dynamics and how these shift. It may be possible to perceive stages of group development by listening. Initially the group may play together in rhythm or aim to fit in with what else is happening musically. Following the development of trust in the group, individuals may begin to take risks musically producing more dissonance and differentiation in pace. Later, there may be more movement between different styles of playing and flexibility of musical roles. The music expresses the essence of the group as it is in that moment and as it changes over time.

Pavlicevic (1995) writes about using musical evidence to discern interpersonal processes in clinical improvisation: "The information is right there, within the improvisation. We need the sensitivity and astuteness to 'read' this information accurately" (p. 173). Music created by a group is a powerful expression of their group dynamic. 


\section{SECTION SUMMARY}

Group work has been examined by many theorists and this has led to detailed delineation of developmental sequences for group process over time (Brabender \& Fallon, 2009; Tuckman \& Jensen, 1977; Wheelan, 2005). These processes of creating group norms, resolving conflicts and developing cohesion have also been observed and described by music therapists who have worked with groups of adolescents (Rickson, 2001; Aigen 1997; McFerran 2010). These music therapists, among group workers from other fields, have recognised group work as a powerful tool for working with adolescents. The group setting and process can provide opportunities to address the social challenges that are the crux of adolescence: developing a positive self-identity, achieving autonomy, and finding a balance between intimacy with and isolation from others (Malekoff, 2004).

The unique strengths of music therapy as an approach include music's ability to bring people into an awareness of the present; and music's ineffable nature, which in certain circumstances may be experienced as a 'safer' form of expression than using words (McFerran \& Wigram, 2007). These strengths appear promising for application to single sessions of group work, as several authors have highlighted the need for a focus on the here-and now, and for 'safety' and avoidance of conflict when facilitating single-session groups (Yalom, 1995; Manor, 2010; Turner, 2011; Blackwell, 2011).

Making music with others by nature involves interaction. Because of this, music therapists have condoned the use of musical evidence to discern interpersonal processes in clinical work (Pavlicic, 1995; McFerran \& Wigram, 2007). In particular, musical improvisation can be a powerful expression of group dynamic. 


\section{METHODOLOGY}

This section describes my theoretical orientation and methodological approach to establishing an understanding of group dynamics and process within the single-session music therapy groups I was facilitating.

\section{RESEARCH QUESTIONS AND AIMS}

I have aimed to:

- gain new insights into my own music therapy practice, by exploring links and relationships between theory from literature and my observations,

- evaluate and evolve my music therapy practice,

- synthesise my own experiences with the perspectives of existing theory, to generate theory about group process in single music therapy sessions which is grounded in observation.

The research questions identified were:

- What influences group dynamics within single sessions of music therapy?

- How can existing understandings of group process be applied within single sessions of music therapy?

- How are these processes evidenced within each music therapy session?

- How can I best facilitate these open groups, given the changing group dynamics?

\section{EXPLORATORY RESEARCH}

Given the paucity of previous group theory that had been applied to single sessions of any type, my specific research interest in group process within single-session music therapy groups warranted an exploratory approach. This approach is defined by Stebbins (2001) as "a broad-ranging, purposive, systematic, prearranged undertaking designed to maximize the discovery of generalizations leading to description and understanding of an area of social or 
psychological life" (p.3). I aimed to form understandings of and explanations for the phenomena I observed in my group sessions.

Stebbins (2001) says about the emergent findings of exploratory research, that they are "many and varied; they include the descriptive facts, folk concepts, cultural artifacts, structural arrangements, social processes, and beliefs and belief systems normally found there." (p.3). In drawing out these broad ideas, I wanted to describe the music therapy processes I experienced in rich and complex detail and consider some ways these might be drawn together to guide practitioners.

\section{QUALITATIVE SECONDARY ANALYSIS}

Qualitative secondary analysis provided an approach that would allow me to draw on the rich data I had already gathered for clinical purposes. This meant there would be no direct 'research participants' and there would be minimal risk to those implicated in the research.

This kind of qualitative secondary analysis is defined by Heaton (2004) as 'supra-analysis'; it "transcends the focus" for which the data was originally derived, in order to examine a new theoretical question (p.38).

\section{THEORETICAL FRAMEWORK}

I understand knowledge to be constructed socially. I believe the meanings and definitions we create through the exchange of language are co-constructed along with those we are engaging with. This is the key idea of symbolic interactionism, situated within a paradigm of constructivism (Bloor \& Wood, 2006).

Symbolic interactionism is both a theory about human behaviour and an approach to inquiring about human conduct and group behaviour (Annells, 1996). The three basic premises for this perspective were outlined by Blumer in 1969 (cited in Annells, 1996):

- The meanings that we hold for a 'thing' (object, situation, person etc.) are derived from social interaction

- These meanings determine what actions we take towards the various 'things'

- As we deal with a situation, we interpret and modify the meanings we hold. 
Throughout this process of exploratory research, I have engaged with interpreting and modifying the understandings I held about groups in single sessions of music therapy. It is important to acknowledge that my findings have been constructed by me, around my own perspectives and assumptions. This is made more complex by the fact that in this study I have been both the music therapy practitioner and the researcher, looking into themes arising from my own practice.

Although analysing data after it had already been gathered for clinical purposes placed a distance between my involvement in the sessions and my analysis of them, my own processes (actions, understandings, assumptions) were still involved in both steps. Not only have the findings arisen from what I interpreted in the data; the group sessions themselves and my clinical records of them were originally influenced by my involvement in, and subjective experiences of, the sessions.

Clinicians and researchers need to be self-aware and to recognise the impact that their assumptions and behaviour have on therapy and research processes. It has therefore been essential to maintain a clinical journal as I engaged in clinical practice, as recommended by Barry \& O'Callaghan (2008). The entries have noted my subjective thoughts, interpretations and expectations; elucidating my own perspectives and prompting me to question some assumptions. They have been a tool for self-insight and healthy critique of the things I noticed and interpreted.

\section{STUDY DESIGN}

DATA COLLECTION AND SOURCES

Clinical data was gathered as part of my usual clinical practice at the adolescent facility. These data sources included:

- Clinical observation notes from sessions

- Recordings and analyses of improvisations created in the group sessions

- My own journal entries. 
As I was a student with a particular interest in group dynamics, my clinical data at times contained more detail about group interactions than might be usual in other clinical circumstances.

NUMBER OF SESSIONS ANALYSED

It was decided that clinical data would be analysed until the analysis reached a point of 'saturation' (see below). The size of the study limited the amount of clinical data that could be engaged with. However, I anticipated that the detailed and rich data generated from five to ten clinical sessions would provide sufficient insight.

NUMBER OF IMPROVISATIONS ANALYSED

Musical analysis would be carried out on any improvisations the groups agreed to have recorded. While group improvisations occurred in several of the sessions, only the seventh group agreed for these to be recorded. Detailed musical analysis was done on the three improvisations arising from this particular group.

\section{ANALYSIS OF THE MUSICAL DATA}

When analysing group improvisations, I was guided by the Music Therapy Group Improvisation Analysis Model (MTGI-AM). This model was devised by McFerran (2003) especially for use with adolescent music therapy groups. It involves five levels of listening in order to arrive at a description that highlights the most salient aspects of the improvisation. The five levels were:

- an open listening to gain broad impressions of the music

- a listening directed by the musical properties of the improvisation

- an intramusical level, directed by Bruscia's "Improvisation Assessment Profiles (IAPs)" (1987) describing connections between musical elements and group members' contributions

- a listening focused on the group leader's music

- the final listening. 
At each level a narrative description of the improvisation is written from the perspective of that level of listening. In the final stage, the previous narratives are summarised and combined to distil the most essential aspects of the improvisation as experienced by the listener. I assumed that information about interpersonal dynamics in the group could be inferred from the improvisational musical evidence.

At McFerren's (2003) suggestion, I simplified the intramusical level of listening by using an abbreviated version of the IAPs (Bruscia, 2002) to draw out relevant intramusical aspects, rather than the full version (Bruscia, 1987). The abbreviated version asks a series of questions that relate to the themes (congruence, variability, salience, autonomy, tension, integration) originally described by Bruscia. For my purposes I did not answer those questions relating to 'autonomy', as these focused strongly on individuals' behaviours. I wanted to avoid this individualistic focus for ethical reasons (see ethical issues).

In reading Bruscia's "Response to the Forum Discussion of the IAPs" (2002) I was reminded of the importance of sectioning the improvisations and considering each section separately. I therefore added a level of listening to the process of music analysis which focused on breaking the improvisation into sections based on changes in the improvisation's most salient elements.

As I reflected on this analysis process and what it could tell me about group process and dynamics, I became increasingly interested in what was happening for the group as changes took place in the improvisation. I therefore decided to focus another level of listening intently on the process of change between sections.

This level of listening outlined some of the ideas of leading and following inherent in the 'autonomy' theme, but with a focus on the group as a whole rather than drawing attention to each individual.

My final process of music analysis was:

- open listening

- $\quad$ sectioning

- musical properties 
- intramusical, guided by Bruscia’s abbreviated IAPs (2002)

- group leader's music

- describing the process of changes in the improvisation

- final listening, leading to synthesis and summary.

An example of an improvisation analysis is provided in appendix one.

\section{THEMATIC ANALYSIS}

I explored the narrative data using thematic analysis, following a process outlined by Rickson (2011). Thematic analysis is described by Gibson \& Brown (2009) as "the process of analyzing data according to commonalities, relationships and differences across a data set" (p. 127).

I began by reading my data sources several times and beginning to note my thoughts and reactions in the margin of the documents. This is called taking analytic memos (Ely, Vinz, Downing \& Anzul, 1997) and I continued this process throughout the qualitative analysis. One purpose of these memos was to identify emerging themes. Another purpose was to remind myself of pieces of data that were related or contrasting and to raise questions.

My research question: "how can existing theories about group process be applied within single sessions of music therapy?" provided an exploratory starting point. I began open coding each separate piece of data, using a deductive approach of looking for key ideas from the literature that were apparent in the clinical data. I drew on theory from literature describing:

- $\quad$ group processes and dynamics in longer-term closed groups and

- group work in music therapy.

A list of key ideas I was keen to notice and identify is provided in appendix two.

Coding involved labelling sections of data as belonging to a particular category. Over time, as I drew new links between concepts, the initial categories developed, broadened, were combined and reshuffled. There were limitations in the theories I used as a deductive starting 
point, in that those developed for a verbal form of therapy needed adapting and interpreting to be relevant to music therapy. Also, theories based just on group work with adolescents did not account for the adult staff members who were also members of the music therapy groups I facilitated. To mitigate these limitations, I needed to critically consider which aspects of theories were most or least relevant to my clinical situation and to aim not to force data to 'fit'. I also needed to be open to new ideas that arose from the clinical data itself. The process of coding therefore also became inductive, involving ongoing dialogue between pre-existing theory and new insights (Glaser \& Strauss, 1967).

After coding each individual piece of data, the coded sections were recombined with other pieces of data relevant to their 'category', using a large spreadsheet. This allowed me to further scrutinize the codes, as they related to each other across data sets. Clearly labelling and describing each category and criteria for inclusion or exclusion from it, prompted further recombining, shuffling and narrowing of the codes. I was guided by the questions: "what kind of picture am I developing through my categories and codes?" "What analytic work does this code do that that one doesn't?" and "what is the relationship of this code to my initial conceptualization of group process and dynamics and how does it help me to understand what I am seeing?” (Gibson \& Brown, 2009, p. 135). This process, called axial coding (Rice \& Ezzy, 1999), led to a more stringent description of each category and its subcategories.

An example of the thematic analysis process is provided in appendix three.

\section{SATURATION}

I recognised saturation as a point where I was finding no new themes in the data. Because of the level of detail outlined in my clinical notes and journal entries, I found I reached a point of saturation after coding six sessions. One more session was coded, including three musical analyses of the group's improvisations. This session illustrated and coloured many of the ideas that had been drawn out from earlier sessions, but no new codes arose from it. In total, data from seven separate sessions of group music therapy was coded. All sessions took place between April and July. 
I have striven to ensure that my usual clinical practice was not interrupted or disrupted by the research process in any way.

I gained informed consent from the facility for secondary analysis of my clinical data for research purposes. I also gained informed consent from group participants who have been represented in a clinical vignette and from all involved in audio files of clinical improvisations. In one instance, due to illness and the brevity of an adolescent's engagement in music therapy, it was not practical to administer full information and consent forms to him. A process of assent was used and informed consent later gained from a staff member who worked closely with the adolescent, on his behalf. A similar process was used to gain consent on behalf of a student staff member represented in the vignette, who completed their work at the facility and could not be contacted. The information sheets and consent forms used are presented in appendix four.

I encountered several difficulties around gaining informed consent from all the group members represented. When individuals were due for discharge or due to finish student placements, I had no or very little time to talk with them about the research. There was also very little space for them to consider their involvement. Adding to these issues, the adolescents involved in groups were acutely unwell, complicating the question of their consent. To mitigate these risks and protect the safety of those involved, I have presented the clinical vignette and findings with as little focus on individuals as possible. Some potentially meaningful details have therefore had to be omitted. No real names have been used.

This project has been approved by the Massey Human Ethics Committee, HEC: Southern A Application - 11/41. 


\section{SECTION SUMMARY}

An exploratory approach was adopted for this research. Data was collected as part of usual clinical practise and a process of secondary analysis was carried out. The size of the study limited the amount of data that could realistically be engaged with, however the richness and detail of the data collected meant that a point of saturation was achieved after analysis of material from six sessions. The analyses ultimately included MTGI-AM musical analysis of three group improvisations; thematic analysis of clinical notes from seven group music therapy sessions; and thematic analysis of journal entries which reflected on those sessions. I was implicated as both a clinician and researcher in this project. I needed to recognise the impact my assumptions and behaviour had on therapy and research processes; journaling was an essential tool for self-awareness. 


\section{FINDINGS}

This exegesis demonstrates that group process is evident within single sessions of music therapy open to both adolescents and mental health staff. I will begin by presenting a clinical vignette. This written description of a session, created by expanding and refining my written session notes and musical analyses into a narrative, is included here to give the reader a complete picture of the group dynamics and process from one session, and to give context to the more general findings presented later.

The main findings are presented as a narrative synthesis of the thematic analysis. Each category represents one key concept from the data that had an impact on group dynamics. The categories are parent to a number of themes, which describe more fully what impacted on the group dynamic and how. A few excerpts from my journal entries will be included throughout, to illustrate certain insights.

Categories relating to environment, group management and leadership, motivation, connection, and intrapersonal aspects, and how these impacted on group dynamics, will be discussed in turn. Key ideas about group process, which is understood as the way group dynamics shifted over time, are also discussed under these categorical headings. A summary of findings related to group process is also presented in bullet point form in appendix five.

Logical relationships between the major categories and each theme are shown in fig. 1; a few themes are equally relevant to two categories. Due to the complex nature of groups, all the elements interlink in some way. For clarity, they have been drawn out separately here, though they are not separate in reality.

\section{VIGNETTE}

The recreation room is cold but bright, with couches, beanbags and some artwork on the walls. I have moved the couches around enclosing just half the room as the space is so large. In the middle of the room on a colourful box are a variety of percussion instruments. There are also three guitars, a ukulele, a tenor recorder and an American Indian flute. I have a flute beside me on a coffee table.

We have just finished the 'morning meeting' in the same room and one of the adolescents, 'Sven', has stayed in the room with me while I set up. He picks up some instruments, shakes 
or taps them and asks where they're from. Two student staff members join us. One picks up a drum and begins tapping a rhythm. Another staff member comes into the room, looks around then leaves again.

I choose a large hand drum and join the rhythm which is already happening in the room, saying, "that's a neat beat, let's keep it going while we wait to see who else is coming." The beat grows louder and stronger then quickly dies down and stops as the staff member from before returns with two more adolescents. One, 'Oliver', who is a skilled guitarist, reaches immediately for a guitar and sits down. The other looks around a little awkwardly and is called out by a doctor almost immediately.

The two adolescents still have instruments in their hands and are 'fiddling' on them. I ask the staff members to choose an instrument too and suggest we warm-up by taking turns to play two notes each. I begin, playing guitar, and the group watch each other, hesitantly taking their turn. At first we try to keep a steady beat, but it is disjointed. I tap quietly on the body of the guitar and the group gains some momentum. Oliver makes some bold contributions, playing two very high, fast paced notes. This is reflected by some of the group members who also play higher on their instruments or leave different amounts of space between their two notes. We make it around the group three or four times and I suggest we continue playing but more freely, still taking notice of what each other is doing. Oliver picks a few notes cautiously then launches in to the beginning of a metal riff. Sven, playing a tambourine, stops playing and looks at the person next to him as though waiting for his turn. I join the metal riff and the other staff members tap or shake along seeming uncertain. Oliver plays a few hurried chords and stops, continuing to pick the odd note. I say to the group 'let's go back to two notes each' and play the tonic note from the young man's riff twice. The staff member next to me continues in pace and we make it securely around the group.

I give the group the choice to play some songs or to keep playing the instruments, gesturing to my folder of songs. Oliver asks enthusiastically to keep jamming and begins talking about symphonic black metal. We have had satisfying improvisations together in an individual session and his passion for metal music is apparent.

In a previous group session, Sven had said he 'hated' it when we improvised together, but has taken part with a smile on his face. I know from other staff and from my own time spent 
around the unit that he often reacts against structure imposed by (or even suggestions from) others.

We have a conversation about what features of symphonic black metal we could use in our playing, considering our limitation of having only acoustic instruments. Oliver identifies several key features about this style of music he enjoys.

\section{IMPROVISATION ONE : 'SYMPHONIC BLACK METAL'}

Two guitars and a drum play quietly in a mostly disconnected way as I set up the recording device. One of the guitars is played by a staff member who is finger picking a chord pattern, the other guitar is played by Oliver, who is also finger picking but at a faster pace and using different chords. Sven plays a drum. His playing is steady and consistent, but at a different pace again. As I begin to talk to the group, the drumming continues briefly and then stops.

"So, in the style of symphonic black metal, to the best of our ability" I say and Oliver gives a short laugh, "we'll move around this way adding in one instrument at a time, ok? Wait until you've heard what the other instrument is playing for a little while, and then come in." I reiterate the stylistic elements we have identified. "We're going to play fast, and there'll be high sounds and low sounds, but there might not be a whole lot of change throughout the whole thing."

I had asked if Oliver would start us off. However, he spends some time looking for a pick, which I don't have, then gives a nervous laugh saying to a staff member "you start us off. I'm lost". The staff member is not familiar with metal music and seems uncomfortable. I ask if I can start, and both the staff member and Oliver look relieved. I tell them I will begin by playing a rhythm on the low 'e' string of the guitar, but after Oliver has begun to play I will take my guitar away. He says "sweet" and we begin.

There is a gradual building of texture, with one new sound being introduced at a time. As more players join, there is a sense of instability, which then settles as I repeat the rhythm pattern on the low 'e' string. The rhythmic base is stable and group members maintain the same rhythmic motifs with very little change. Mostly the individual's motifs are separate but related to each other, although one of the group member's drums in particular stands out as beating steadily at a pace that contrasts with the rest of the group. There is a significant shift after 4 min 30, when a new, faster paced rhythmic figure is introduced by a group member 
and immediately matched by others. Throughout this second section, different group members hold the rhythmic grounds in turns. There is greater melodic interest and variety. Some ideas that I introduce on the flute are taken up and extended by a quiet guitar and kalimba. The group very gradually decrescendos and drops away. I hold an extended trill in the lower octave of the flute as the hand drum continues to beat. The hand drum is the last to finish, ending with a drum roll.

The group is really keen to hear themselves. We listen back through to the improvisation, making a few comments as it plays. They seem pleasantly surprised by what they hear, remarking, "We sound quite good", "it's really rhythmic" and "I'm surprised, it's not too bad, we keep together pretty well”.

Sven says he couldn't hear his own playing and tries a few other instruments to find one that may come across more clearly.

We discuss a style for the next improvisation and decide on 'Spanish'. Again, Oliver makes this suggestion. One of the staff members picks up a maraca and shakes it above her head in a way suggestive of flamenco. We begin one at a time in the same way as for the previous improvisation.

IMPROVISATION TWO: 'SPANISH'

The Spanish theme is apparent throughout the improvisation. Two guitars keep a driven rhythmic pace. Maracas and egg shakers keep time and embellish the piece with extended shakes. Some initial pushing of pace is quickly resolved and the group 'falls in'. I play rising and falling melodic lines on the flute, which gives definition to the group's phrasing and centres the tonality strongly on e minor. A significant change comes after 2 min 40, when I put down the flute and pick up a tambourine. This change is met with a number of other group members also switching instruments or initiatiating new musical ideas. For example, a guitar player initiates new chord choices, another group member picks up a kalimba and the maraca player shakes in long extended shimmers rather than keeping the beat. I repeat a rhythm on the tambourine, despite this the group sounds like it lacks a solid foundation. The group comes together again very near the end, decrescendoing and finishing naturally.

Again, we listen back to the improvisation. I point out the changes I hear throughout it. Some of the group members make comments about each other's playing - "that's a cool rhythm, 
was that you?" I ask the group which improvisation they feel they were more 'together' in. They say they sounded more together in the first one, but that they took more musical risks in the second.

Sven asks about a drum that is covered in animal fur - "what animal do you think it is? Where is it from? Maybe it's tiger. Can you play 'eye of the tiger'?"

I play the melody from the tune 'eye of the tiger' on flute but say I don't know the whole song. One of the staff members begins the 'eye of the tiger' riff on guitar and the adolescents and I loosely sing a chorus along to it. Oliver watches the staff member's hands and then joins him playing the same chords.

We have about ten minutes left and I ask the group if they want to jam one last time or if we should finish with a song. They say, "Let's jam again".

IMPROVISATION THREE - 'EYE OF THE TIGER'

As I set the portable recording device in the centre of our couches, most of the group members have instruments in their hands and are 'noodling' in a loosely connected way. Oliver confidently begins the 'eye of the tiger' riff and the improvisation has begun before I sit back down.

A guitar repeats the motif from the song 'eye of the tiger' and this syncopation is copied by a number of percussion instruments. The sound is energetic and rhythmic, with texture and volume steadily building as more instruments are layered over each other. A change comes after 1 min 20, when a tom-tom drum and my tambourine drop out, thinning the texture. Quiet melodic lines are played on a kalimba and a guitar. These new melodic ideas are not based on the 'eye of the tiger' theme but still fit within it. We alternate between the very thickly textured, highly rhythmic sound of the first section and shorter periods of quiet playing with more melodic prominence and less stable rhythmic grounds. These quieter sections follow key changes by the guitarist playing the main riff and sound like possible endings. During the last of these changes, the group drops away leaving one guitarist 'noodling' on the upper strings, accompanied by a quiet sustained drum roll played on a hand drum with just two fingers. The guitar plays a cadence but the soft drum roll continues. I ask the group if that's the end and there is a cacophonic release of random sound by all group members, led by a loud drum roll. 
There is no time to listen back to this improvisation. However, perhaps because the improvisation finished with such emphasis, I feel it is ok to end the group there. They help me put a few instruments away and then leave the room ready for morning tea.

\section{BRIEF REFLECTION}

This session was not a typical group session, in that both of the adolescent participants already knew me and had some experience of music therapy. Gaining informed consent to present material from music therapy sessions of this nature is extremely difficult. Group members might be too unwell to give consent, for example, or they might leave the service before they have had time to consider what is being asked of them. It is for this reason that an atypical session has been presented. This group was also comfortable with their improvisations being recorded, which has allowed more musical detail to be included in the description.

It was partly my previous knowledge of the Sven and Oliver and partly my own tendency to err on the (sometimes ambitious) side of offering groups a lot of control, that prompted me to give them choice from very early in the session. In the groups studied, it was unusual for adolescents to assert their preferences and interests as clearly as Oliver and later in this session, Sven did. This group also reflected verbally on their improvisations with apparent comfort, which was also unusual.

The group was initially highly self-conscious which resulted in disjointed playing, but throughout the session they came to be able to play cohesively together. They matched elements of each other's playing and took risks. By the end, they did not need to be explicitly 'led' and were able to begin the final improvisation themselves.

Improvisation provided an opportunity for free and uninhibited expression. The group members played more freely, taking more risks and initiating more changes in the music as they established cohesion. Through their playing, group members were able to support and be supported by each other and when listening back to themselves they showed interpersonal insight.

The session drew on the adolescents' interests and abilities, with each of the themes for improvisation coming from the young people present. Sven, the quieter of the two, was able 
to assert a choice and have this valued by the group near the end of the session. Through drawing on their interests and abilities and encouraging choice, the adolescents' identities were acknowledged and their autonomy encouraged.

FIG. 1: CATEGORY AND THEME RELATIONSHIPS

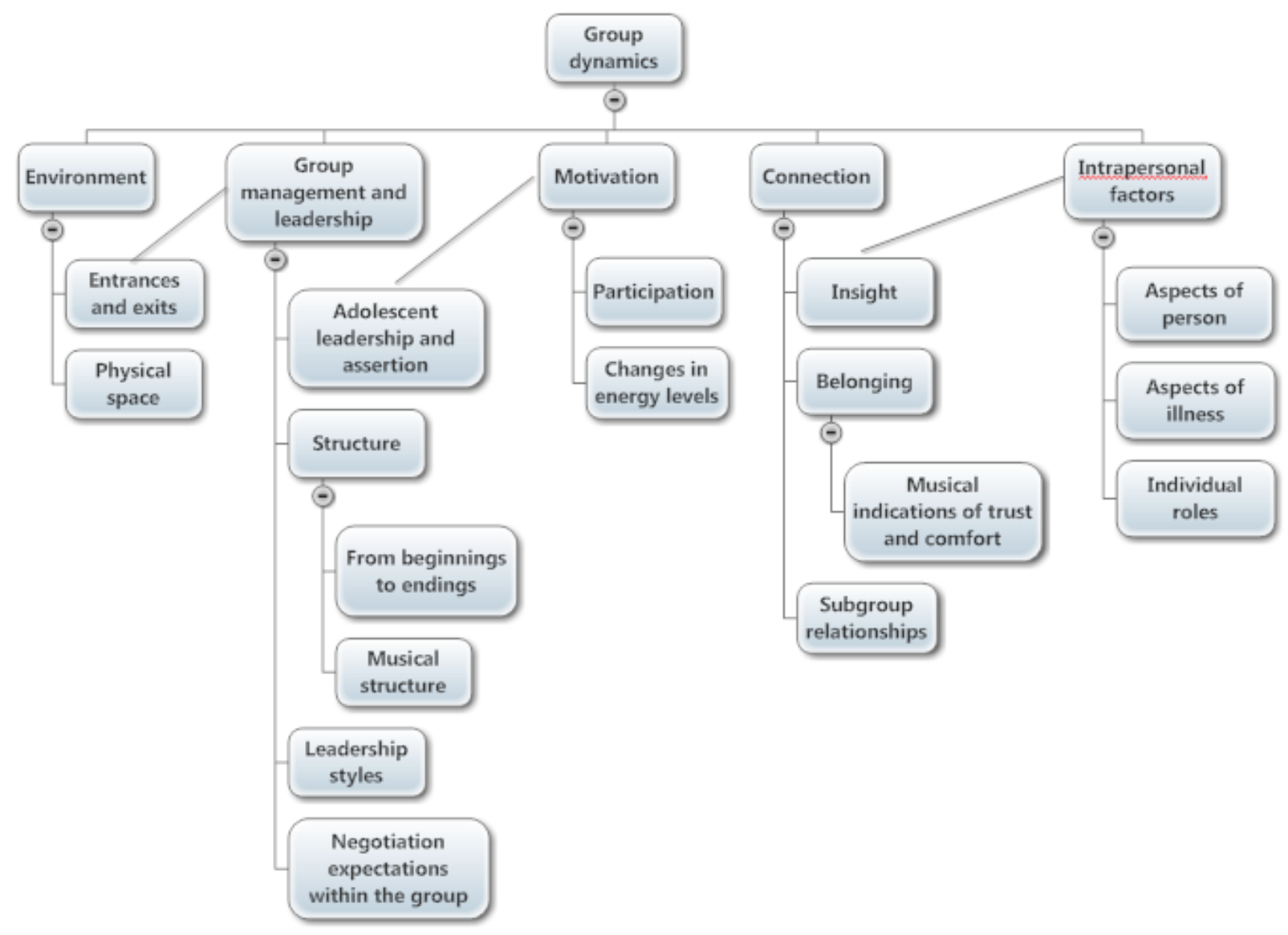


The physical environment and wider institutional contexts had an impact on group interaction.

PHYSICAL SPACE

\section{Positioning and movement was an important form of non-verbal communication.}

Most sessions took place in a large room, although two spontaneous groups happened in a smaller, cramped room. The larger space invited more movement, around the room, between instruments and towards or away from the main group. The vignette demonstrates how I prepared the room by moving couches closer together, enclosing a smaller space. In the smaller room, group members tended to remain at a particular instrument. They moved when prompted by a verbal request, or to leave the room.

I communicated invitations and expectations physically, for example by leaving instruments in the middle of the room. My positioning was also an important communication. In one group, I was still setting up as group members entered the room and had my back turned to them. They chose instruments and were quietly improvising together by the time I turned around. While setting up I was not able to lead or join them; however the room felt calm. My casual and non-expectant position may have made the group seem less threatening.

Adolescents moved closer to each other when they needed emotional support. Physical closeness between group members could cause others to feel excluded. Including a physically distant group member required taking a directive approach, creating a clear role for them. This was successful when I also supported the group member musically. Requiring others to include a group member sometimes took interrupting the music, for example "hang on, you guys are the accompanists, you need to support your performers by looking to them before you start! Otherwise we won't go at the same time."

In order to be away from others, adolescents moved to the other side of the room, or behind a barrier such as a couch. Despite physical distance or barriers, some adolescents listened for a full session. Others made musical contributions from a distance, which connected with the rest of the group. 
Adolescents' verbal communication about their enthusiasm (or otherwise) did not always match with their movement. For example, they verbally expressed disinterest or a belief that they could not do it, yet moved immediately towards an instrument.

ENTRANCES AND EXITS

Changes in group membership and reasons for change, had an impact on group interaction. (See also group management and leadership).

The complex schedules of the inpatient unit meant adolescents and staff often needed to leave the group to attend some other appointment. Adolescents also left the groups for a myriad of other reasons. When very unwell, they found it difficult to focus for the full hour. An emotionally challenging activity could also prompt an adolescent to leave, as could dissonant music.

When an individual left, the change in dynamic could (but did not always) have a profound impact. Losing someone who had been integral to the music caused the group's energy to drop, whereas losing someone who hadn't been fully included by others did not alter the remaining members' interactions.

Sometimes when an adolescent left the group, they returned shortly after. I assumed the young people were self-regulating by taking a break.

When individuals joined partway through a session, the impact of their addition to the group depended on how comfortable they were with the environment. Oliver already knew me and was an enthusiastic guitarist; he immediately joined in with the group. When new members who were less comfortable joined, the session's 'flow' could be disrupted. New group members needed to know what was going on and this could mean repeating instructions several times. When others had already begun to achieve some cohesion, I found it particularly challenging to balance the wider group's needs with those of an individual who had just arrived. 
Negotiation of leadership, control and shared expectations had an impact on group interaction.

\section{LEADERSHIP STYLES}

\section{Team leadership roles impacted on group interaction.}

The groups required various styles of leadership, depending on the strengths of group members and their ability to take on autonomy. My leadership styles sat on a continuum between confident direction and handing over responsibility to the group, between controlling the group's interactions and allowing the sometimes chaotic dynamics to play out, between providing structure and just 'going with the flow'.

I made decisions about how much direction to give based on intuition. As a student, I did not always get this in-the-moment sizing up of a group's needs and potential right. For example, a song was requested which I knew but could not coordinate singing. I asked for help from the group, but no one joined in and without conviction this activity died. It was not a fair expectation to look to the group for musical support.

Individuals responded to direction differently. For example, some joined the rest of the group musically when I created a clear role for them. Others disengaged from or left the group when any pressure or attention was placed on them. I felt it better to just allow adolescents who were less familiar with the environment the space to listen and observe.

I felt uncomfortable about stopping any of the adolescents' musical responses, but it was sometimes necessary to firmly direct an individual so that the rest of the group could continue successfully. It was important to share leadership roles among group members and to create these roles as soon as possible for those I directed to take a back seat. Adolescents left when they did not get these opportunities soon enough.

When group members were not listening to each other and the overall sound was chaotic, firm direction could bring the group into awareness of each other's sounds. Procedural instructions for who was to begin followed by whom, encouraged group members to match each other's music. 
I often gave the group choices as a way to hand some responsibility over to members while checking that the activities were enjoyable. Oliver made a clear and enthusiastic choice to continue improvising. This level of autonomy was unusual. Generally, individuals did not clearly state their preferences, although asking each group member separately achieved more responses than asking the broad group.

Another leadership dilemma was how much security the group needed and what topics could be dealt with safely. When potentially triggering topics such as suicide came up, I felt anxious to settle the group into a 'safe space' again but also wanted to acknowledge the individual.

STAFF INVOLVEMENT

\section{Staff members took on varying levels of contribution and shared leadership.}

I felt it important to fully include staff members by recognising their choices and musical contributions along with the rest of the group. Some staff had specific musical skills and drawing on these was a great resource. Staff musicianship provided a stronger and more energetic musical 'backdrop' than I could provide alone. At times staff participated at the same level as adolescents, at others they took on greater leadership roles.

Having another staff member available was absolutely necessary in a surprising situation. After discovering a giant weta on their chair, an adolescent ran from the room. They needed support, but the rest of the group could not be left alone. One of us was able to leave the room and encourage the adolescent back, while the other dealt with putting the weta out the window and keeping the remaining group settled.

At one point, the team decided another staff member would co-facilitate with me. I felt disempowered that they had not consulted with me but had just presumed that would be ok. In hindsight their decision was probably made based on the facility's whanau focus that everyone works together. My attitude shifted when the designated staff member approached me to respectfully talk over the session, both before it and following. I realised how helpful it may be to have assistance with providing a musical framework, setting up, packing away and reflecting after the session.

Managing a new co-leading relationship along with the unknown group membership and dynamics from week to week was challenging. I wrote that there were "several new bridges 
to cross and it's a little like beginning again." Shared leadership meant balancing how and when I relinquished or retained control of the group. I found our co-leading most comfortable when we were able to converse with each other through improvised music. I felt this was a vehicle to negotiate and resolve issues of shared leadership.

This co-leading relationship didn't continue throughout the year, but a question, "is this my role or can it be theirs?" remained prominent in my thinking. In the vignette, the group began their final improvisation before I sat back down. They no longer needed me to explicitly lead them.

\section{STRUCTURE}

\section{The structures of a session impacted on group interaction.}

I wrote in my journal:

"My experience so far is that more structure tends to work better. The adolescents stay in the room and participate for longer this way. I also want to give them as much autonomy as possible, so it is a difficult balance. I feel like at times perhaps I'm being overbearing, but also that I'm not able to hold together all the seams, especially if I leave them to their own devices".

This was equally true for managing the group from activity to activity in a session and within the music created.

FROM BEGINNINGS TO ENDINGS

\section{Structure impacted on group safety and participation.}

I often used a highly structured warm-up activity. There was high participation for these activities, although as can be seen in the vignette, having each person play separately caused hesitation. Activities that avoided the anxiety and awkwardness of spotlighting an individual were more effective at putting the group at ease.

In the vignette, I changed structure during the activity, suggesting we play more freely. This caused confusion and we 'fell out' of the fragile connection we were making. Changing structure during an activity was never successful. When instructions were not completely clear, this also caused confusion and led to a less cohesive musical outcome. 
I felt it important for the groups to leave feeling comfortable. Ending with a structured, undemanding activity was helpful. In one group, ending with a familiar song facilitated the participation of the group's quietest member.

The times I felt least comfortable, and individuals seemed most likely to leave, were the 'spaces' in between each music activity. I wrote "the empty spaces feel charged and heavy, the room and the silence gaping". Music held the group, whereas silences were more difficult to navigate.

Preparing a whiteboard with the session's intended schedule written on it was helpful in containing the group through these spaces. However, it made it more difficult to 'go with the flow' and accept spontaneous suggestions.

\section{MUSICAL STRUCTURE}

\section{Patterns of rhythm, harmony and form contained the group.}

The adolescents told me the music was good when it was "consistent". I interpreted that to mean they appreciated stability and structure could be satisfying for them.

Retaining stability sometimes meant compromising my response to an individual's contributions. For example, in order to keep the overall stability of a song, I needed to change chords before one adolescent was able.

Staff members could sometimes play a bass line or chords, or keep a steady beat, while I took another musical role. This created a 'fuller' sound than I could produce alone and allowed adolescents to step into and out of the music without affecting its stability.

Some small gestures could provide enough stability for the group to lean on and play off. In the vignette, quiet tapping on the body of a guitar was all that was needed to gain momentum. In improvisations, another way to provide musical structure was to shape the group members' music with more clarity. During the 'Spanish' improvisation, my flute melody more clearly defined the phrasing and tonality that had been laid out by others.

The more people playing the harder it was to hold the group together. Clear and repeated rhythms were sometimes effective, as in the 'symphonic black metal improvisation'. However, repeated rhythms did not always hold a group in sync, as in the 'Spanish' improvisation. 
NEGOTIATING EXPECTATIONS WITHIN THE GROUP

\section{Knowing what was expected increased group safety and participation.}

Some participants had not experienced music therapy before and would not have known what to expect. I was aware this could cause uncertainty and anxiety. Group members were generally hesitant (see adolescent leadership and assertion). Initial activities may have reassured group members, as adolescents and staff alike became more comfortable as a session continued.

Clarifying what was ok to be doing released tension and brought more participation. When playing known songs, I told the groups it was ok to sing, to play, or to listen. When improvising, having a thematic idea or style to play to was helpful. The 'symphonic black metal' genre was discussed with the group described earlier, who identified some types of sounds that could fit within it. This gave them ideas of what to expect and of what they could contribute.

The sounds resulting from groups were not like the recorded music that the adolescents listened to. It was necessary to clarify that we did not need to sound like recorded music; otherwise adolescents had a negative reaction to our 'noise'.

Group members brought expectations from their previous musical experiences too. One group clapped following a song as though it had been a performance. I worried this represented a barrier between performer and listener which I did not want for the groups.

I also brought expectations and goals with me. In one spontaneous session I challenged the adolescents to listen better to each other, they felt there was no point in trying as they were leaving soon. Our understandings of the session's purpose were different and so my goal was not achieved.

ADOLESCENT LEADERSHIP AND ASSERTION

\section{Adolescents took on varying levels of autonomy and control. (See also $\underline{\text { motivation }}$ ).}

Although I leaned towards wanting to give the group as much autonomy as they were able to take on, group members often looked to someone else's direction rather than asserting an idea themselves. Adolescents handed responsibility for a choice back to someone other than themselves in several ways: de-selecting an option rather than positively choosing one, 
deferring to another group member and making half a choice, for example by choosing a band but not a song.

Adolescents who knew the environment well were more forthcoming. Following their lead, others tended to contribute more too. Perhaps this was because their peer was able to model how and they were able to observe that the group accepted contributions.

It was easier for adolescents to join in an activity than it was for them to begin it. Oliver was very hesitant to begin the 'symphonic black metal' improvisation. Once I had begun it, he joined in confidently and maintained a strong rhythm.

Adolescents who knew me well also asserted themselves by challenging my leadership, or by demanding for leadership. "You're the facilitator, so facilitate!" They also defied group norms. One adolescent joined us, walked directly through the middle of the room where other group members were sitting upright on chairs and sofas and lay down on a beanbag in the corner.

Having a mix of adolescents who were new to the group and who were more familiar with it posed a dilemma for leadership. Those who were comfortable were ready to take on more responsibility, whereas those who were newer required firm structure to clearly understand what was expected and accepted in the group and so feel safe in their participation. A variety of different musical spaces, both structured and freer, needed to be created in each session in order to capture the contributions and assertions of different adolescents involved.

\section{MOTIVATION}

Motivation to contribute impacted on group interaction.

PARTICIPATION

\section{Group members chose their own level of involvement.}

This was reflected in their choices to stay or to leave, to make decisions or defer them to someone else, to lead or follow and also in their level of active contribution to each activity. When they chose not to actively contribute this didn't mean they weren't engaged. Some adolescents remained listening for the full session, but did not wish to actively play an instrument or sing. 
As well as familiarity with the environment, adolescents' level of participation was affected by their personality and aspects of their illness (see intrapersonal factors).

Occasionally, limitations of available technology hindered an adolescent's ability to share themselves with the group. For example, the speakers available did not have a suitable connection for all portable music devices. After a disappointment they made few attempts to actively contribute.

Staff members also chose their own level of involvement. I encouraged them to contribute as I felt this engendered greater participation from others. They brought their own expertise to the session and intuited when to allow adolescents to take the lead and when to model more strongly. However, new staff members were unsure of what was expected of them. Staff were struck by self-consciousness too and sometimes declined to take part in activities.

Modelling by staff and peers was one mode of encouragement that persuaded adolescents to become more involved. Others responded to more direct encouragement such as being offered to have an instrument passed to them. I felt it important to be wary of drawing the group's attention to an individual and to clearly leave the option to decline my offer. When adolescents felt pressured they left the room or withdrew from communicating with others.

CHANGES IN ENERGY LEVELS

\section{Group energy levels had an impact on, and were impacted by, individuals' motivation to contribute.}

The overall level of energy in a group was affected by how many group members were present, their personalities and aspects of their illnesses, their comings and goings and by their level of active contribution to the group. As mentioned earlier, when a group member left the room the energy level often dropped.

When adolescents took on more ownership of the session, energy was higher. In the vignette, the group was hesitant and our connections with each other fragile until Oliver made an enthusiastic decision to continue improvising. All the following improvisations, based on personal interests of the adolescents, were highly energetic. 
Singing together also increased energy. There was high active contribution while singing popular songs; some individuals smiled, laughed and sat more upright where earlier they had appeared lethargic or uninterested.

When an activity ended with high levels of engagement, individuals were more likely to make suggestions and so take ownership of the next activity. This in turn increased energy.

When a highly structured activity had been going for a while, the group's energy sometimes shifted down a notch, perhaps reflecting boredom. I often gave a choice when I sensed this shift. However, individuals rarely made assertive choices on the back of low overall group energy.

\section{CONNECTION}

\section{Existing and emerging relationships between group members impacted on group interaction.}

\section{SUBGROUP RELATIONSHIPS}

\section{Dynamics between a subset of group members had an impact on the wider group.}

Some group members interacted more closely with each other than with the rest of the group. These partnerships were often helpful for the individuals, who were able to support each other musically and in other ways, by passing each other instruments or by backing up their verbal contributions to the group.

When there was a tight subgroup of two or more adolescents this could cause others to feel excluded (see physical space). The resulting dynamic was disruptive to others when the friends were more involved in their own interaction than in interaction with the rest of the group. Bridging the gap between the friends and the others required a directive approach, providing structured opportunities to work together.

Some group members already had negative relationships with others. Behaviour resulting from this, such as swearing or reprimanding, could bring a feeling of tension and discomfort to the whole group. 
Staff had broader knowledge of the adolescents from spending all week with them. When I did not give immediate and clear boundaries around behaviour another staff member did. This was helpful in keeping the group a safe space for others, however it left me wondering about our balance of leadership (see leadership styles) and whether I would have drawn the same boundaries. Some of the adolescents brought difficult behaviour to most of their interactions with others; it was necessary to accept a level of negativity in order to connect with them.

\section{BELONGING}

Individuals negotiated their own place within the whole group. Cohesion resulted when all individuals found a way to belong.

Some individuals made a place for themselves by taking on a social role (see individual 'roles'). Others jostled their way in with humour. Humour among the adolescents had a competitive edge, a feeling of constantly trying to do one better in order to belong.

Others created a space that was separate from the group, by removing themselves physically (see physical space). Individuals also used subtle means to set themselves apart from the group, for example through comments which highlighted differences between themselves and others. After one session I wrote "there was something about (adolescent's) comment which alienated her from the others, an undertone of "you're different to me."”

Positive feedback from peers encouraged adolescents to give more of themselves, for example by explaining the personal significance of a piece of music. Positive feedback showed their peers' acceptance of them and strengthened their sense of belonging.

The groups enjoyed hearing themselves play together and reflecting on what they heard strengthened their sense of being a group. In the vignette they were surprised by how 'good' they sounded and how well they kept together.

MUSICAL INDICATIONS OF CONNECTION, TRUST AND COMFORT

\section{Musical connections promoted belonging.}

Early in a session, individuals tended to play in a way that was disconnected from others. In the vignette, just prior to the first group improvisation, their 'noodling' was more disconnected than the same un-solicited playing later in the session. 
Individuals also tended to play in a way that was disconnected from others when a new person joined the room, or when exploring potentially uncomfortable themes. At these times, adolescents continued their own playing, undeterred and uninfluenced by others. The result was chaotic.

I found it was sometimes possible to weave connections between group members' music even amongst this chaos, for example by matching my playing to the rhythm of one group member and the tonality of another. Another technique was to subtly accentuate any commonalities between their playing. This required that I provide support that did not overpower their contributions. However, there were times when chaotic sound persisted, apparently without connection between group members.

Without an established culture of listening for each other, the group could swamp an individual's playing. It was possible to support the individual to be heard by synchronising with their playing. When group members showed little awareness of each other's music, each person also tended to finish playing at a different time.

Moving from this state of chaos into making music that was more responsive to each other meant finding common ground. Playing music that was structured, 'safe', 'comfortable', and 'in time' facilitated this for some groups. While first establishing a musical connection, group members tended to stick to the safety of what they knew, by repeating the same motifs and playing rigidly in time and in key. Early in the 'symphonic black metal' improvisation, the group stuck to the safety of maintaining the same motifs, with little change for four and a half minutes.

Once common ground was firmly established, individuals were able to match aspects of each other's playing. Group members matched the length and shape of phrases, played motifs that were rhythmically or melodically related to others' and crescendoed or decrescendoed with the group. They were able to incorporate new elements into old motifs, contributing lines that were separate but related to each other. Later in the 'symphonic black metal' improvisation, the group showed greater role flexibility and more variety in their playing. This added to an overall group sound which was greater than the sum of its parts. Groups that played with this level of cohesion were able to naturally find an ending point to a song or improvisation together. 
After achieving a level of musical cohesion, the group sound often became somewhat chaotic again, as a result of individuals taking risks. Less 'organised' sounds could result when group members changed instruments, played with dissonance, introduced new musical ideas, or took on different roles in the music. The latter part of the 'Spanish' improvisation seemed to lack a solid foundation because of the many new musical ideas and changes of instrument. However the group was able to finish naturally together, suggesting they were listening closely to each other. Although it did not sound like it; I felt this role flexibility, risk-taking and ability to blend old ideas with new ones did represent cohesion and trust in the group. I assumed that testing boundaries, both in the group and musically could be a positive thing.

The 'eye of the tiger' improvisation suggests that the group negotiated closure musically. There were several points at which they could have chosen to end but did not. Group members finished playing at different times to each other, before all joining a final cacophonic drum roll. I wrote "I think the ABABABA form of the improvisation may have been in denial of the end of the session and that the drum roll represented an eventual acceptance of this transition."

INSIGHT

Groups' willingness to explore intra- and inter- personal processes verbally was dependent on cohesion. (See also intrapersonal factors).

I found that individuals rarely gave verbal interpretations of what was going on for them or of what they perceived in the group. When I asked for comments it often felt like "there wasn't much meaningful to say and any comments that came were pretty benign.” In retrospect, I often asked myself whether we had needed to talk about it at all.

However, there were times when individuals did comment meaningfully on the significance of a piece of music for them or on what they perceived in the group. For example, while the group listened back to the 'Spanish' improvisation, individuals commented positively on each other's playing. This showed acknowledgement and acceptance of each other. They also reflected that they had sounded more 'together' in the previous improvisation, but in this one they had taken more risks. Their insights showed they were highly aware of the process the group was going through. 
Invariably in the data, individuals only made significant comments after the group had reached a level of cohesion. When one of them responded meaningfully to my question or probe, this was after other comments had been freely made in the group. In the vignette, I made casual comments as the group listened to themselves, also leaving space for others to comment or to just listen. Perhaps this modelling without pressure was effective at creating a level of verbal comfort in the group.

\section{INTRAPERSONAL FACTORS}

The group was affected by the characteristics and behaviours of its members.

\section{ASPECTS OF PERSON}

\section{Consistent features of individuals (skills, personality etc.) impacted on group interaction.}

My decisions around how to lead the group were affected by any previous knowledge I had of them. Where I was aware of individuals' abilities, it was possible to create musical roles that drew on these. Many of the group members brought skills, interests and strengths to the group that added very positively to the session. Oliver's skills on guitar and interests in symphonic black metal and Spanish music gave the group the momentum to successfully improvise together. Sven contributed his own interests to the group later in the session, suggesting the song 'eye of the tiger'. A staff member's knowledge of this song allowed us to successfully follow through with his suggestion.

All the adolescents had needs due to their acute illnesses. Some had needs in addition to this, socially, physically or cognitively. Perhaps because all the individuals were so diverse, those with extra needs did not become a focal point for the group.

\section{ASPECTS OF ILLNESS}

\section{Group members' illnesses had an impact on group interaction.}

Some of the adolescents on the unit were affected by depression, anxiety, social phobia, paranoia, avolition, or anhedonia. This affected their energy level and ability to engage with the group. 
Given my limited previous knowledge of the adolescents, it was often difficult to know what aspects of their behaviour were due to illness and what aspects were more consistently a part of them. For example, if an adolescent 'drifted' during an activity, it was difficult to know whether this was due to psychotic phenomenon, whether they were having difficulty concentrating, or they were simply uninterested. One thing that was clear was that an hour was a very long time for some of the adolescents to retain focus. When concentration was too much of a demand, adolescents left the group or removed themselves physically to watch the group or sleep.

\section{INDIVIDUAL 'ROLES'}

\section{Social roles had an impact on group interaction.}

Individuals took on particular social roles. These could be disruptive to the needs of other group members, for example, by dominating and not allowing them to be heard. An example was the role of a 'performer' who was not able to tolerate listening to others for long. Having more than one 'performer' in the group caused significant conflict and alienated group members who were not moved to fight for their space in the music. Keeping a clear structure around whom would play or lead an activity, while giving every group member a turn at this 'performing' role, was successful at mediating this dynamic.

Individuals' roles could also be helpful to others. Adolescents who were approaching wellness and were comfortable in the group were able to model that it was ok to take part and to enjoy themselves. Sometimes they took on a role that was quietly supportive of others. Where the adolescent had musical sensitivity, this was powerful at complementing the whole group's music and bringing a sense of stability and 'fullness'.

Opportunities to listen back and reflect on music created by the group led to individuals making new role choices. In the vignette, Sven chose a new instrument after listening to the group's first improvisation, preferring an instrument that would allow him to be heard. 
A developmental group process was evident within single sessions of music therapy. For example, a process of moving from disconnection, to establishing common ground, developing musical cohesion, then taking risks and negotiating closure, was audible within group improvisations. Group dynamics were affected by the physical environment and wider institutional contexts; by the leadership styles and structures implemented; the contributions of group members; the quality of existing and emerging connections between individuals; and aspects of the individuals themselves. The structure of music provided stability, mediated energy levels and presented opportunities for individuals to develop leadership and autonomy. Groups became more autonomous and took more risks as musical and interpersonal cohesion was established. 


\section{DISCUSSION}

There is strong movement towards increasing community-based support for tangata whai ora while decreasing the amount and length of hospitalisations (Sarafino, 1997). It will therefore become more necessary that acute crisis services understand how best to implement shortterm interventions. The group format is an opportunity to reach many people at once and therefore has economic and resourcing advantages. Despite these imperatives, the body of knowledge on the processes and facilitation of single-session and open groups is small (Wheelan, 2005; Turner, 2011). Currently this field can be considered exploratory and emerging. Increased knowledge about groups in single sessions will be helpful for a variety of practitioners, including music therapists, who work in this way.

The findings of this exploratory study suggest that group dynamics do change even within a single session. Group interrelationships may be affected by the physical environment and wider institutional contexts, by the leadership styles and structures implemented, by the contributions of group members, by the quality of existing and emerging connections between individuals and by aspects of the individuals themselves. This supports the idea that groups interact at a number of levels: individual, sub-group and whole group (Manor, 2010) and suggests that factors external to the group, such as the wider institutional context, may also have significant impact. Any of these levels of interaction may bring about change in the group process.

In this study, the process of change is reflected most strongly in the data from musical analysis of group improvisations, which can be linked with existing models of developmental group process (see fig. 2).

While a period of disconnection from others is not represented in the developmental stages laid out by Tuckman \& Jensen (1977), Dies (1996), or Skewes (2001, cited in McFerran, 2010), the emergence of disconnected and egocentric music making is described by Rickson (2004). This was the starting point for the boys in her study who began working together using improvisational methods. It is possible that disconnection, rather than being unique to groups using improvisation, is uniquely visible through musical improvisation. Disconnection would probably be apparent when most groups began working together if they were not mediated by the structuring actions of the group leader. 

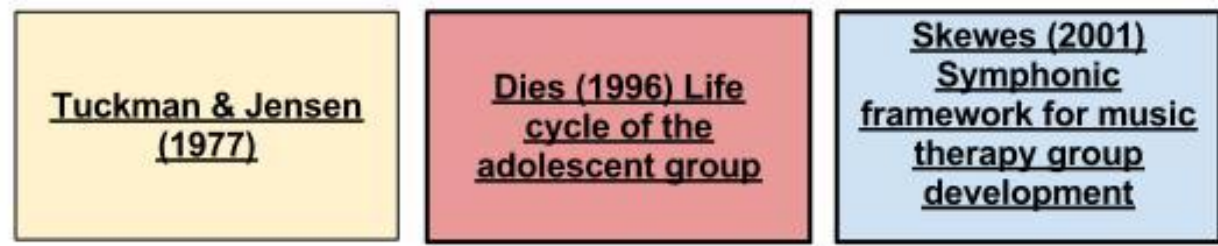

Music analysis of group improvisations

DISCONNECTION:

egocentric playing

FORMING: establishing boundaries and expectations

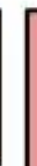

INITIAL

RELATEDNESS:

establishing safety and

first connections

STORMING: testing

boundaries

NORMING: developing group norms, a sense of 'groupness'

PERFORMING: group co-operates to achieve its goals

ADJOURNING: period of reflection and closure

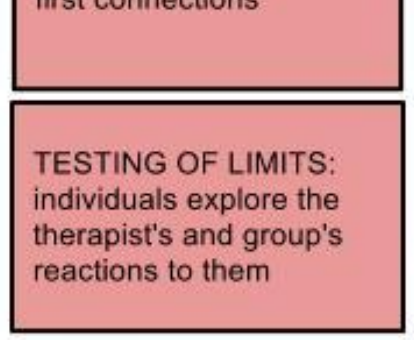

RESOLVING
AUTHORITY ISSUES:
trust develops in the
group as individuals are
not penalised for
asserting themselves

\section{WORK ON THE SELF:} group achieves greater responsibility over itself. Interaction between group members increases

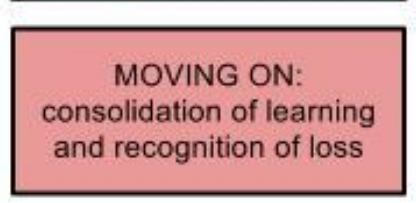

INTRODUCTION: high

level of structure

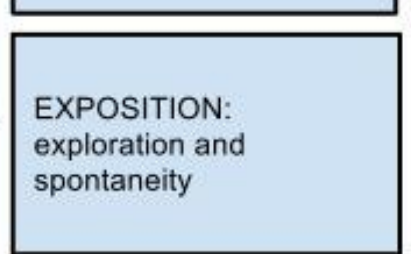

DEVELOPMENT:

conflict and

confrontation of issues

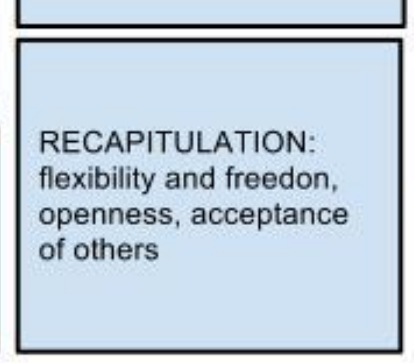

CODA: closure,

independence from the leader
COHESION: listening to others, role

differentiation, variety

FINDING COMMON repetition

RISK TAKING: new ideas, dissonance, concurrent rhythms, role changes, can sound chaotic. Group is still able to match each other in broad musical shifts

\section{NEGOTIATING}

CLOSURE: some

disconnection reappear
GROUND: stability and elements of

The improvisational stage of finding common ground can be compared with the stages of forming, initial relatedness and introduction in the above theories. Each stresses stability and structure, with the establishment of clear expectations and group safety. The variety and role differentiation which appear in the next improvisational stage, which I have called 'cohesion', link most closely with exploration evident in the exposition stage of the symphonic framework. There is a focus on development of trust and support during the exposition, which is evidenced in the music analysis by the group's ability to listen and match each other's music. A focus on trust does not appear in the other theories until later, which 
suggests that earlier development of trust may be a unique aspect of groups that use music. More research would be needed to clarify this.

Testing boundaries could be interpreted in the musical analysis of my study. For example, during the 'symphonic black metal' improvisation, one drum could be clearly heard beating at a different pace to the rest of the group. This occurred relatively early in the group process, which would fit with the models of Tuckman \& Jensen (1977) and Dies (1996). However, limit testing was more clearly indicated later in the session as individuals began to take musical risks.

By the final improvisation, the group described in the vignette had achieved a level of autonomy which allowed them to begin playing spontaneously. This seems to reflect the level of cooperation and group responsibility described in the performing and work on the self stages, though would also fit within the symphonic framework's earlier stage of exposition. Significant conflict did not arise in this group and nor was it addressed, suggesting that, at least in terms of the symphonic framework, this group remained in the exposition phase.

The theories above all describe processes for groups who meet together over many sessions. It is logical that a group that meets just once may not move through all the stages described and likely that such a group would not move beyond the first or second stage. However, musical evidence suggests that the elements of trust, cohesion and risk-taking that, in theory, occur later in the developmental process did emerge, at least for the group described. It may be that single-session groups reflect elements of a complete group process, while not fully embodying stages beyond the first few.

This proposition is supported by the group's return to disconnected playing as they negotiated closure. Perhaps the group was briefly able to foray into trust and connectedness, but unable to sustain this through the transition of the end of the session. It is understandable that this transition could be challenging for the group. First, they must come to terms with the knowledge that the group will cease to exist (Wheelan, 2005), and second, they must prepare themselves to return to the chaotic environment of the ward (Manor, 2010). Distancing themselves from others towards the end of a session may even be an adaptive strategy for group members. Manor (2010) and Hope (2011) discuss the need for single-session groups to end with a relatively superficial level of connection to aid this transition. It may be that 
distancing occurs during a closure phase for longer-term groups too, as this certainly happened in the adolescent group described by Aigen (1997).

In the context of a single-session group, distancing oneself in order to avoid the inevitable pain of losing that relationship is an idea that is analogous with issues of attachment. Some of the adolescents involved in the music therapy groups had diagnoses of attachment disorder and it is likely that many others had anxious or ambivalent, rather than secure, attachment styles. Early life trauma and non-secure attachment styles have a connection with experience of depression, anxiety and psychosis (Gilbert et al., 2011) so it is logical to assume there may be a high rate of non-secure attachment styles among acute inpatients.

I noted that some adolescents brought difficult behaviour to most of their interactions and this caused tension in the group. An adolescent with negative attachment representations may mistrust others and show a lack of empathy (Pearce, 2010). It might also feel uncomfortable for them to experience interpersonal connection and this could cause them to 'act out'.

The single-session group is destined to meet only once before confirming the expectation of 'abandonment' that people with attachment issues may hold. However, single-session groups are not necessarily counter-indicated for these individuals. Gilbert et al. suggest that therapy may be advanced by "improving ways of accessing... interpersonal safeness" (2011, p.252). Safeness in these groups could be promoted by avoiding conflict or directing it towards the group leader where possible (Blackwell, 2011), keeping a focus on the here-and-now rather than the myriad of issues related to a person's past or future (Yalom 1995) and by fostering cohesion and acceptance (Turner 2011; Blackwell, 2011).

McFerran (2010) noted that cohesion may be a less useful indicator of success in groups that are not together long-term. However, the particular need for interpersonal safeness in singlesession groups suggests to me that group cohesion is still a relevant focus. My data indicates that cohesion led to greater support between peers and to individuals having confidence to take risks and share more of their identity. Invariably, the groups were only comfortable to reflect verbally on their experiences once a level of safety had been established through cohesiveness. Musical cohesion was not always achieved or sustained, but for groups that did manage this level of togetherness it was a powerful therapeutic factor. It was a vehicle for connection and acceptance, for cooperation and interpersonal learning. 
My understanding of group cohesion is of a sense of whole group belonging, combined with group members' ability to cooperate and take on roles that contribute to a greater whole. This is closely linked with ideas of establishing trust and creating an 'interactive entity'. It is worth noting that my understanding of group cohesion has come primarily from working with single-session groups. For facilitators who work with groups that meet longer term, cohesion might have further or different meanings.

Adolescents who were already familiar with me, had an existing relationship with active music making, or who knew the ward environment well were more forthcoming in the groups. They were more easily able to join in when a group had already begun to work together and were able to take on leadership roles. They were also more likely to test boundaries and challenge my leadership. This ability for autonomy, which often contrasted with other group member's self-consciousness, suggests to me that group process may also occur on an individual level. That is, rather than completely beginning the process again each session as suggested by Blackwell (2011), an individual who has previous connections with aspects of the group may move more quickly into behaviour indicative of storming, norming or performing or the later phases of other group developmental models.

The implications for the group leader are that leadership style should take into account both how long the group has been working together as a unit and how comfortable individuals are within the group. When anxiety and chaos (without specific purpose) prevails, structure and a directive approach is indicated. When individuals appear comfortable, a less directive approach may be appropriate to leave open the opportunity for empowerment. In the group I described earlier, a shift from more to less directive facilitation appeared to inspire the development of autonomy in the group.

The young people showed greater comfort as the music therapy environment became familiar to them. This allowed them to participate more fully and actively in the group's activities, to build relationships with each other and with music, as well as to take opportunities for leadership and empowerment. This suggests that, when possible, it is beneficial for young people with mental health issues to attend more than one session of group music therapy, even when the group membership changes each time.

With each new or lost member, the overall dynamic could shift significantly and this might necessitate a shift in leadership style. Leadership of single session or open groups would 
therefore be enhanced by an ability to move flexibly between styles of facilitation, an idea that is supported by Turner (2011). For me, the dilemma of how much structure and how much freedom to provide was constant. Yalom (1995) affirms that the balance of these aspects is essential: too much or too little structure will inhibit the group's growth. In practice, group leaders are likely to make these kinds of decisions in the moment, as I did. Intuiting the best decisions for group growth, while accounting for individual need, is likely to take significant clinical experience. Clinical supervision was valuable for reflecting on this balance in my groups.

Beginning music therapy practitioners might be guided by the psychodrama model of warmup, action, reflection (Manor \& Dumbleton, 1993; as cited in Manor, 2010). This provides a structure for the beginning, middle and end to a group in which the middle section is the most demanding and cathartic, while the beginning and ending make use of clear direction (Blackwell, 2011). My data supports the idea that adolescents are not always open to verbal reflection and can find silences difficult to tolerate (McFerran, 2010). A cooling down activity might therefore substitute for the reflection stage in certain adolescent groups. Adolescents may not always reflect overtly (ibid.), but as my group description demonstrates, they may nevertheless develop insights into interpersonal processes. Experiencing these may be enough.

My findings indicate that a change in membership could cause the group to revert to playing in egocentric and disconnected ways, possibly representing a disruption in the group's process and development of cohesiveness. This does suggest that the groups' ability to begin to work together was compromised when members came and went within a session. To maximise the potential for a group's development within a single-session, it would be beneficial to hold firm boundaries of time, place and membership.

At this particular facility, holding such boundaries was extremely problematic. The choice to stay or leave a group was often beyond the individual's control. For example, young people were called out to see a doctor, or staff members were needed elsewhere. It was typical for both staff and young people to come and go during all TDP programmes, for many reasons, and I needed to take care to work within this prevailing culture. I felt that the risk of creating rejection for an individual, by not allowing them to join or leave a group partway through, usually outweighed the risk of minimal cohesion for the group as a whole. 
Some adolescents left when the group sound was uncomfortably dissonant or emotionally confronting, for example during an improvisation on the theme 'anger'. Perhaps the use of improvisation is best reserved for groups that are more stable or that have a number of members who are more comfortable in the group. Rickson's (2004) study showed that a group that had already achieved a level of cohesion through instructional music therapy methods made an immediately successful transition to the use of improvisational methods. The group's beginning stages may be better negotiated with highly structured activities involving clear expectations rather than the use of improvisation, which encourages individual interpretation, responsibility and freedom.

However, those groups that are able to successfully use improvisational methods may find them valuable for group development. The group described in this exegesis used improvisational music to express aspects of their identity as they played in styles they were personally interested in. They used improvisation to connect with and support each other, to explore a variety of roles and take risks and even to negotiate closure. This is evidence that group developmental change not only occurs within single sessions of music therapy, it may occur within single improvisations. Further research would be needed to determine whether group developmental change could occur within a single music experience of some other kind.

Establishing a clear sense of group purpose is referred to in the literature as an important task for beginning a group (Turner, 2011; Manor, 2010; Malekoff, 2004). Even for a group that meets just once, without much time to negotiate purpose, clarity is considered essential. Establishing a clear purpose may aid the 'therapeutic alliance' (Turner, 2011) between therapist and group members. Ethical practice also demands that any person taking part in therapy has a clear understanding of the purpose (Turner, 2011; Music Therapy New Zealand, 2006). My data showed that not having a clear sense of purpose was a significant barrier to engagement. Even in spontaneous sessions, the group leader should try to briefly address and clarify with group members their purpose for meeting.

Further recommendations to music therapists who facilitate single sessions are summarised in appendix six.

This piece of research has focused solely on uncovering detail about the dynamics and process in seven music therapy groups, which all took place at the same facility and with 
people belonging to the same 'population': adolescents with acute mental unwellness. While the descriptions and recommendations provided may be of interest and relevance to other music therapists or group workers, findings cannot be generalised to groups from another facility, population, or therapy type.

For ethical reasons it was necessary to focus on the whole group rather than the individuals within it. For example, aspects of Bruscia's IAPs (1987) that focused on individual behaviours rather than group trends were omitted. Given that the individual is an important level of a group's functioning, omitting this data will have limited the depth that could be drawn about group dynamics.

Further research in the field of single-session group dynamics and process is necessary if we are to build a thorough understanding of how well the groups are serving their purpose and how best to facilitate them. Future research might focus on determining whether the improvisational stages of development outlined here occur for other groups, on participants' experience of cohesion in single sessions or on how single-session groups develop autonomy. 


\section{SECTION SUMMARY}

Music is created moment by moment and has a unique ability to bring people into awareness of the present (McFerran \& Wigram, 2007). Music therapy may therefore be a very appropriate intervention for use in acute mental health wards where it is essential the therapeutic focus be on the here-and-now (Yalom, 1995). The safety of expression through music lends itself well to work with adolescents, who may find verbal methods threatening. In music, nothing need be clearly articulated but others may implicitly understand emotional content. Music offers opportunity for expression of identity. Additionally, playing a differentiated musical role within a cohesive group may be a potent way for adolescents to achieve individuation while still belonging. This challenge captures the crux of adolescence (Malekoff, 2004).

Music can bring people into an awareness of the present, be a vehicle for safe expression of emotions and identity and offer opportunity for playing a valued individual role in a group creation. In an acute mental health unit for adolescents, music therapy is often practiced in a group environment that is subject to frequent changes in membership. In this setting, many individuals experience music therapy in a one-off session. An understanding of group dynamics and process involved in single music therapy sessions will allow therapists to tap into the full potentials of music. 
Developmental group process is evident within single sessions of music therapy open to both adolescents with mental illness and mental health staff. For example, a process of moving from disconnection, to establishing common ground, developing musical cohesion, then taking risks and negotiating closure was audible within group improvisations. Levels of structure, clarity of expectation, familiarity with environment and other participants, and stability of group membership can have an impact on group cohesion. 'Safe' activities can engender comfort in a group and encourage engagement. Individuals may invest more in music therapy groups when they hear themselves as part of a greater whole and when trust is strengthened through peer support. The structure of music can provide stability, mediate energy levels and present opportunities for individuals to develop leadership and autonomy. Groups may become more autonomous and take more risks as musical and interpersonal cohesion is established.

Group dynamics are affected by the physical environment and wider institutional contexts, the leadership styles and structures implemented, the contributions of group members, the quality of existing and emerging connections between individuals, and aspects of the individuals themselves. However, there are economic and resourcing advantages to therapy in the group format, and single-session or open group interventions are particularly relevant for acute hospital wards. Further research in the emerging field of single-session group dynamics and process is therefore warranted, and will be necessary if we are to build a thorough understanding of how well these groups are serving their purpose and how best to facilitate them. 


\section{REFERENCES}

Aigen, K. (1997). Here we are in music: One year with an adolescent creative music therapy group. New York: MMB Music, Inc.

Annells, M. (1996). Grounded theory method: Philosophical perspectives, paradigm of inquiry, and postmodernism. Qualitative Health Research, 6 (3), doi:10.1177/104973239600600306

Bandura, A., \& Walters, R. H. (1963). Social learning and personality development. New York: Holt, Rinehart \& Winston.

Barry, P. \& O’Callaghan, C. (2008). Reflexive journal writing. Nordic Journal of Music Therapy, 17 (1), 55-66.

Blackwell, D. (2011). Ships in the night: The 'open group' for clients on the waiting list. Group Analysis, 44(3), 247-265. doi: 0.1177/0533316411401803

Bloor, M., \& Wood, F. (2006). Keywords in qualitative methods. London: SAGE Publications Ltd.

Brabender, V. \& Fallon, A. (2009). Group development in practice. Washington, DC: American Psychological Association.

Bruscia, K. E. (2002). Response to the forum discussion of the "IAPs". Nordic Journal of Music Therapy, 11(2), 72-82. Retrieved from http://dx.doi.org/10.1080/08098130209478049

Bruscia, K. E. (1987). Improvisational models of music therapy. Springfield, Illinois:

Charles C. Thomas Publisher, Ltd.

Bunt, L. (1994). Music therapy, an art beyond words. London: Routledge.

Corder, B., Whiteside, L., \& Haizlip, T. (1981). A study of curative factors in group psychotherapy with adolescents. International Journal of Group Psychotherapy, 31, 345-354. 
Dies, K. (1996). The unfolding of adolescent groups: A five-phase model of development. In Kymissis, P. \& Halperin, D. (Eds.), Group Therapy with Children and Adolescents (35-53). Washington : American Psychiatric Press.

Ely, M., Vinz, R., Downing, M. \& Anzul, M. (1997). On writing qualitative research: Living by words. Bristol, PA: The Falmer Press.

Erford, B. (2010). Group work : Processes and applications. London: Merrill.

Erikson, E.H. (1980). Identity and the life cycle. W.W. Norton \& Company.

Foulkes, S. (1983). Introduction to group analytic psychotherapy. Exeter: BPCC Wheatons Ltd.

Gibson, W. J., \& Brown, A. (2009). Working with qualitative data. London: SAGE Publications Ltd. Retrieved from http://srmo.sagepub.com/view/working- withqualitative-data/d1.xml?rskey=QedHlk\&row $=3$

Gilbert, P., McEwan, K., Matos, M., Rivis, A. (2011). Fears of compassion:

Development of three self-report measures. Psychotherapy: Theory, Research and Practise, 84 (3), 239-255. Doi: 10.1348/147608310X526511

Glaser, B., \& Strauss, A. (1967). The Discovery of grounded theory. Chicago, Aldine.

Goodman, K. D. (2007). Music therapy groupwork with special needs children. Springfield, Illinois: Charles C. Thomas Publisher, Ltd.

Heaton, J. (2004). Reworking qualitative data. London: SAGE Publications Ltd. Retrieved from http://srmo.sagepub.com/view/reworking-qualitativedata/n3.xml?rskey $=$ WnWFyI\&row $=0$

Henderson, S. M. (1983). Effects of a music therapy programme upon awareness of mood in music, group cohesion, and self-esteem among hospitalised adolescent patients. Journal of Music Therapy, 20(1), 14-20.

Hendricks, C. B. (2001). A study of the use of music therapy techniques in a group for the treatment of adolescent depression. Dissertation Abstracts, 62(2-A). 
Hibben, J. K. (1991). Identifying Dimensions of Music-Therapy Activities Appropriate for Children at Different Stages of Group Development. Arts in Psychotherapy, 18(4), 301-310.

Jex, S. M. \& Britt, T. W. (2008). Organizational psychology: A scientist- practitioner approach. New Jersey: John Wiley \& Sons.

Kim, S., Kverno, K., Lee, M. E., Park, J. H., Lee, H. W., \& Kim, H. L. (2006). Development of a music group psychotherapy intervention for the primary prevention of adjustment difficulties in Korean adolescent girls. Journal of Child and Adolescent Psychiatric Nursing, 19(3), 103-111.

Le Bon, Gustav (1897). The crowd: A study of the popular mind. Retrieved from http://books.google.co.nz

Malekoff, A. (2004). Group work with adolescents, second edition, principles and practice. New York: The Guilford Press.

Manor. O. (2010). The single session format: Common features of groupwork in acute psychiatric wards. In J. Radcliffe, K. Hajek \& J. Carson (Eds.), Psychological groupwork with acute psychiatric inpatients (pp.132 - 155). London: Whiting \& Birch Ltd.

McFerran, K. (2010). Adolescents, music and music therapy. London: Jessica Kingsley Publishers.

McFerran, K., \& Wigram, T. (2007). A review of current practise in group music therapy. British Journal of Music Therapy, 16(1), 46-55.

McFerran, K., \& Wigram, T. (2005). Articulating the dynamics of music therapy group improvisations. Nordic Journal of Music Therapy, 14(1), 33-46.

McFerran-Skewes, K. (2003). Contemplating the nature of adolescent group improvisations. Voices: A World Forum for Music Therapy, 3(3). Retrieved from https://normt.uib.no/index.php/voices/article/view/133

McFerran-Skewes, K. (2000). From the mouths of babes: The response of six younger, bereaved teenagers to the experience of psychodynamic group music therapy. The Australian Journal of Music Therapy, 11, 3-22. 
McGrath, J. E., \& Tschan, F. (2004). Temporal matters in social psychology: $\quad$ Examining the role of time in the lives of groups and individuals. Washington, DC: American Psychological Association.

McGrath, J. E. (1991). Time, interaction, and performance (TIP): A theory of groups. Small Group Research, 22(2), 147-174.

Montello, L., \& Coons, E. E. (1998). Effects of active versus passive group music therapy on preadolescents with emotional, learning, and behavioral disorders. Journal of Music Therapy, 35(1), 49-67.

Motherwell, L. \& Shay, J. J. (2005). Complex dilemmas in group therapy: Pathways to resolution. New York: Brunner-Routledge.

Music Therapy New Zealand. (2006, February). Code of ethics for the practice of music therapy in New Zealand. Retrieved from http://www.musictherapy.org.nz/assets/files/code_of_ethics_feb06.pdf

Nicoll, D. (2008). Music therapy groupwork with special needs children: The evolving process. Arts in Psychotherapy, 35(3), 234-234.

Nitsun, M. (2011). Uses and abuses of theory: A group analytic perspective. European Journal of Psychotherapy and Counselling, 13 (2), 115-127.

Odell-Miller, H. (2002). One man's journey and the importance of time. In Davies, A. \& Richards, E. (Eds.) Music therapy and group work: Sound company, 63-76. London: JessicaKingsley Publishers.

Pavlicevic, M. (2003). Groups in music; Strategies from music therapy. London \& New York: Jessica Kingsley Publishers.

Pavlicevic, M. (1995). Interpersonal processes in clinical improvisation: Towards a subjectively objective systematic definition. In Wigram, T., Saperston, B., \& West, R. (Eds.), The art and science of music therapy: A handbook, 167 - 180. London : Harwood Academic Publishers.

Pearce, C. (2010). A short introduction to attachment and attachment disorder. London: Jessica Kingsley Publishers. 
Rice, P. \& Ezzy, D. (1999). Qualitative research methods: A health focus. Victoria, Australia 3205: Oxford University Press.

Rickson, D. J. (2011). Lecture notes (managing data: thematic analysis). Wellington: New Zealand School of Music.

Rickson, D. J. (2004). Instructional and improvisational models of music therapy with adolescents who have attention deficit hyperactivity disorder (ADHD): A comparison of the effects on motor impulsivity. (Master's thesis, Massey University). Retrieved from http://muir.massey.ac.nz/handle/10179/255

Sandness, M. I. (1991). Developmental Sequence in Music Therapy Groups. Music Therapy Perspectives, 9, 66-72.

Sansom, M. (2007). Improvisation and identity: A qualitative study. Critical studies in improvisation, 3(1), Retrieved from http://www.criticalimprov.com/article/view/48/427

Sarafino, E. (1997). Health psychology: Biopsychosocial interactions. ( $3^{\text {rd }}$ ed.). $\quad$ New York: Wiley.

Stebbins, R. A. (2001). Exploratory research in the social sciences. Sage University Series on Qualitative Methods, Vol. 48. Thousand Oaks, CA: SAGE Publications Ltd. Retrieved from http://srmo.sagepub.com/view/exploratory- research-in-the-socialsciences/n1.xml

Stewart, D. (1996). Chaos, noise and a wall of silence: Working with primitive affects in psychodynamic group music therapy. British Journal of Music Therapy, 10(2), 21-33.

Thygesen, B. (2008). Resonance: No music without resonance - without resonance no group. Group Analysis, 41(1), 63-83.

Towse, E. (1997). Group analysis and improvisation: a musical perspective. British Journal of Music Therapy, 11(2), 51-55.

Tuckman, B. W. \& Jensen, M. A. (1977). Stages of small-group development revisited. Group \& Organization Studies 2(4), 419-427.

Turner, H. (2011). Concepts for effective facilitation of open groups. Social Work with Groups, 34(3-4), 246-256. Retrieved from http://www.tandfonline.com/loi/wswg20 
Ulrich, G., Houtmans, T., \& Gold, C. (2007). The additional therapeutic effect of group music therapy for schizophrenic patients: a randomized study. Acta Psychiatrica Scandinavica, 116(5), 362-370.

Westergaard, J. (2009). Effective group work with young people. New York: Open University Press.

Wheelan, S. (2005). The Handbook of group research and practice. London: SAGE Publications Ltd.

Wood, D. (2009). Group therapy for adolescents: Clinical paper. Retrieved from http://mental-health-matters.com/component/content/article/99

Woodcock, J. (1987). Towards group analytic music therapy. British Journal of Music Therapy, 1(1). $16-21$.

Yalom, I. (1995). The Theory and practise of group psychotherapy $\left(4^{\text {th }}\right.$ ed.). New York : Basic Books. 
APPENDIX ONE

\section{$\underline{\text { Example of improvisation analysis }}$}

\section{Open listening}

The Spanish theme is apparent throughout the improvisation. Two guitars keep a driven rhythmic pace, alternating between E minor and A minor chords. Maracas and egg shakers provide texture and keep time, using a number of rhythms that are often together as well as apart. e.g. marraccas (crothet crothet crothet crothet) egg shaker building. Some initial pushing of pace is quickly resolved and the group 'falls in'. Through the first section, my flute melodies shape the groups phrasing. The flute is grounded in the main tonality and style of the piece but is adventurous in melodic and rhythmic choices, creating interest. A significant change comes at 2:40 when I drop the flute and pick up a tambourine. This change is met with a number of other group members also switching instruments or initiatiating new musical ideas. For example, a guitar player initiates some new chord choices, another group member picks up a kalimba, and the maraca player shakes in long extended shimmers rather than keeping the beat. The tambourine holds a stable rhythm throughout this section - it's possible that this allows group members to be more adventurous in their playing, although the overall effect is that the group feels less 'together'. However, the group decrescendoes and comes to a natural finish.

\section{Sectioning}

There is a major shift in the overall sound at 2:40 when I stop playing the flute and pick up a tambourine. The timbre and texture is affected by this, and the group also begins to take a number of risks. There is another shift at 3:30 as sounds of slapping on the body of a guitar become more prominent, along with a xylophone player who repeats the tonic note. This combination has the effect of anchoring the group, who steadily decrescendo together and come to a natural end. 


\section{Musical properties}

Rhythmic grounds are stable and consistent through the first part, although become somewhat lost through the second part. The rhythm is held through the first section by the group and through the second section by my tambourine. Rhythmic patterns are varied through the first part but always sit within the main beat, occasionally pushing or dragging the pace very slightly but again coming to 'sit in' together.

The piece follows the same one player begins at a time protocol as the previous improvisation, beginning with egg shakers and maracas until very quickly all group members have joined. There is a marked decrescendo towards the end, other than this the volume of the piece stays consistent throughout.

Instrumentation: maraca, egg shaker, three guitars (one played by tapping and slapping on the wooden body), flute, american indian flute, tambourine, kalimba, xylophone, bells. Eleven instruments played by five people. A number of changes are made by players especially through the second section.

The speed of the improvisation is steady throughout, at approx. 120 beats per minute.

The harmonic base is initially around $\mathrm{E}$ minor and $\mathrm{A}$ minor, but becomes somewhat destabilised through the second part, with one guitar player introducing a new key and chords. The guitars are also somewhat out of tune with each other, although they are held together by playing in a similar feel and with rhythms that are more the same than different.

Melodic figures by the flute throughout the first section rise and fall and rest on leading notes which sustain tension. Another melodic figure is introduced by the American Indian flute, although its quiet sound is masked by other instruments. It can be heard quietly in the background throughout the 'change one'. Its sound is anchoring:

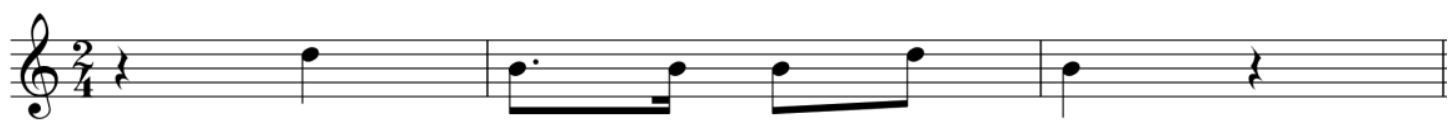

The egg shaker and the maraca sometimes shake continuously, embellishing the improvisation. This is sometimes matched by flute trills throughout the first section, and the 
tambourine in the second section. One guitar player also slaps the body of his guitar on a couple of occasions, which is very stylistically appropriate.

\section{Intramusical: Following Bruscis'a abbreviated IAPs (2002)}

$\underline{\text { Rhythmic elements }}$

Rhythm and basic beat are closely related.

Simultaneous rhythmic parts are closely related, but variable.

Lots of subdivision change. Some subtle meter change, between 2 feel and 4 feel.

Rhythm patterns change frequently, though are consistently grounded in same basic beat.

\section{$\underline{\text { Timbre }}$}

Simultaneous timbres are closely related. The group's instruments fit into four broad categories - guitars, flutes, tuned and untuned percussion, with more than one instrument in each category, and the percussion sounds in particular being very close to each other (maraca, egg shaker, bells and tambourine all played at certain points with similar shaking sounds. Kalimba and xylophone have a similar timbre).

Timbral changes are not frequent, and when group members choose new instruments the overall sound remains similar as there is a reasonably equal spread of instrumentation within the three categories above. The major change is when I switch from flute to tambourine and the major timbre of the flute which had played a lead role through the first section is lost.

\section{$\underline{\text { Volume }}$}

For the most part, each instrument plays at a similar volume. The American Indian flute however plays quietly and is masked by other players.

There is little volume change and the improvisation remains relatively loud throughout, until a decrescendo near the end.

\section{$\underline{\text { Texture }}$}

Simultaneous parts take on very different roles through the first section, but roles are more similar throughout the second section. For example, through the first section a harmonic base 
and main rhythmic ideas are given by the guitars, light percussion instruments keep the beat and also embellish the piece with extended shakes, and the flute creates melodic lines and phrase shape. Through the second section, individual roles are less clearly identified and are less coordinated together. In the third section, a number of group members take on new or different musical roles, for example the guitar player who switches to slapping on the body of his guitar, and the percussion player who switches to playing a repeated tonic note on xylophone which holds the harmonic base of the improvisation.

There is some difference in register between simultaneous parts although this is not marked. The flute forays briefly in to the upper registers. This contrasts with the base- oriented guitar playing of group members but matches the higher pitched sounds of an egg shaker and bells.

There is little change in texture throughout the first section. Textural changes are frequent but subtle throughout the second section and third sections.

\section{Phrasing}

There is a consistent phrase shape of rising in pitch and then falling. In the first section phrase shape is initially laid out by the guitars and then taken up and strongly led by my flute. Throughout the second section, phrase shape becomes less clear. Simultaneous phrases seem to begin and end at different times to each other. Phrasing becomes more consistent and united again briefly during the third section of the piece.

Phrasing is most consistent through the first section, with the flute melody following four bar phrases, timed by the guitars. These phrases are often broken in two sets of approximately two bars by repeating or slightly extemporising on a theme. Through the second section, a consistent four bar phrase pattern is kept by the tambourine, although this is not matched by the rest of the group.

\section{$\underline{\text { Tonal elements }}$}

Melody fits very well into scale and key. An A minor sound is used, which is mainly consistent with a harmonic minor scale but based around the dominant note E. i.e. a mixolydion mode of the A harmonic minor scale.

There are rarely two instruments with a melodic focus playing simultaneously in the improvisation. 
Melody and harmony are closely related and 'fit' together.

Key is very stable throughout the improvisation. In the second section the guitar player initiates a brief modulation into a new key, although this isn't taken up by other instruments and doesn't last. The group returns to the original key to end.

There is a lot of variety in the melody through the first section of the improvisation. The American Indian flute enters during this section, creating a stable harmony by rhythmically repeating a minor $3^{\text {rd }}$ interval between $\mathrm{D}$ and $\mathrm{B}$ (see above). This continues and remains stable throughout the second section. Melodic ideas are much less varied through the second and final sections of the improvisation.

\section{Congruence}

Musical elements are congruent and contribute to the overall 'Spanish' flavour.

The musical elements of the improvisation clearly matched the verbal decision of the group to play in a 'Spanish' style.

There was come incongruence between music and interpersonal relationships - a strong partnership between one adolescent and a staff member was not reflected by their playing.

\section{Group leader's music}

I enter the improvisation on the flute after the rhythmic and harmonic bases have been established, giving group members the opportunity to do this for themselves. My playing matches the volume and energy level of the group. The flute melodies are adventurous and varied but also to some degree containing, as they are based strongly within a scale which contributes to tonal centering. The flute has a lead role through this part of the improvisation and its melodies define and clarify the shape of the group's phrases. The flute often sustains a leading note such as the $2^{\text {nd }}$ or $5^{\text {th }}$ note of the scale used before returning to the tonal centre. This creates melodic tension which is congruent with and intensifies the rhythmic and harmonic tension from the rest of the group. The pattern is consistently to hold the tension, then release it, then hold it, then release it. Early in the improvisation, the flute matches the rhythm of a maraca which is pushing the pace of the rest of the group. This stands out from the rest of the group's playing and there is a strong sense of tension. Both players then settle 
back into the main groove. The flute's melodies are separate and distinct from other individual's music within the group, yet compatible with it.

I shift from playing the flute to tambourine, so shifting my role from a melodic one to a rhythmic one. Initially I synchronise my tambourine rhythms with the guitar players. This role change seems to have the effect of encouraging others to try new things, as the maraca player picks up bells instead, the egg shaker player moves to tapping the body of a free guitar, and both previous guitar players alter their playing, introducing new chords or altering their rhythm patterns. I repeat the same rhythm on tambourine throughout the whole of this section. My tambourine rhythms slow slightly and use less subdivisions as the group calms towards the end.

\section{Processes of change}

Change one: begins at approx. 2:30

The first major change is pre-empted by an egg-shaker player, who subdivides their steady playing building to a very fast paced rhythm pattern, then drops back to a comfortable quaver-beat pattern. My flute phrases match the egg-shaker player - I am unsure who is leading or following - and we both stop playing at the same time. In the following moments, the rhythmic and harmonic base of the group's improvisation stay strong, held by two guitar players, an American Indian flute, and a maraca. I enter the music again, assertively playing a four bar rhythmic pattern on tambourine. On listening again, my tambourine phrase enters before the group has finished their phrase and it is possible that this interrupts or destabilises the group.

\section{Change two: begins at 3:30}

Leading up to this change, the tambourine and one guitar play closely together, using almost simultaneous rhythms and phrasing, another guitar plays something related but doesn't quite seem to 'sync in'. The lower sounds of the guitars and higher sounds of the tambourine contrast strongly with each other and there is not the sense of a harmonic or rhythmic base that there was earlier in the improvisation. A xylophone enters at 3:30 playing the tonic note repeatedly. This seems to provide a centering point, a pitch somewhere in the middle of the existing sounds which connects the separate strands of the group together again. The sounds of slapping on the body of a guitar become more prominent too. 


\section{Final listening}

NB: This narrative was further summarized for inclusion in the clinical vignette.

Section One: $0-2: 50$

The piece begins with the sustained rattling of a maraca and group members join one by one until very quickly all are playing. I sit back from the music until a rhythmic and harmonic base is firmly established, which happens quickly. The two guitars play rising and falling chords in a syncopated rhythm, reminiscent of the 'Spanish' theme. Along with the variety in rhythmic patterns and subdivisions among the percussion players this creates momentum, and the improvisation drives steadily forward.

The two guitars do not play in tune with each other, and there are times when a percussion instrument sits just outside of the pace of the main group. However, each slightly stray element adds a little tension to the overall sound, then returns to 'sit in' with the main feel of the group before long. The percussion instruments keep the beat but also embellish the piece with extended shakes. I play rising and falling melodic lines on the flute, which gives definition to the group's phrasing and centres the tonality strongly around e minor. My playing matches the volume and energy level of the other players.

Throughout this section, the group's volume, timbre and individual musical roles remain very stable.

\section{Change one}

The first major change in the overall sound is pre-empted by an egg-shaker player, who subdivides their steady playing building to a very fast paced rhythm pattern. My flute phrases match the egg-shaker - I am unsure who is leading or following - and we both stop playing at the same time. Other group members continue to play as before. When the flute drops out, a very quiet American- Indian flute whose sounds had previously been masked, becomes audible. This flute repeats the minor third and tonic note which has an 'anchoring' effect. I enter the music again with an assertive four bar rhythm pattern on tambourine, which synchronises with the guitars. 
Section two: $2: 50-3: 30$

This change is met with a number of other group members also switching instruments or initiatiating new musical ideas. The maraca player picks up bells instead, the egg shaker player moves to tapping the body of a free guitar, and both previous guitar players alter their playing, introducing new chords and altering their rhythm patterns. Despite my repeated tambourine motif, this section of the improvisation feels like it lacks a solid foundation.

Whereas in the first section, instruments were paired in timbre - two guitars, two flutes, two hand drums, an egg shaker and a maraca - in this section musical alliances and roles seem much less clear. There are frequent textural changes as new sounds enter. The most prominent sounds are those of the very high tambourine and bells, and the low sounds of the bass strings on guitar.

\section{Change two:}

A xylophone enters at 3:30 playing the tonic note repeatedly. This provides a centering point, a pitch somewhere in the middle of the existing sounds which connects the separate strands of the group together again. The sounds of slapping on the body of a guitar also become more prominent, taking over the main rhythmic role.

Section three: $3: 30-4: 08$

As the guitars and tambourine drop away in intensity, a Kalimba can be heard playing a repeated note which complements the xylophone. The group decrescendos together and slows a little, coming to a natural end. 


\section{APPENDIX TWO}

\section{Starting points for thematic analysis}

These are the ideas from literature that I was aware of prior to commencing analysis. They were used as a deductive starting point for coding clinical data.

Musical indications of group dynamics

Role flexibility

Musical risk taking

Flexibility in musical style (McFerren and Wigram 2002)

$\underline{\text { Stages of chronological group process }}$

Initial relatedness

Testing of limits

Resolving authority issues

Work on the self

Moving-on (Dies 1996)

OR

Forming, Storming, Norming, Performing, Adjourning (Tuckman \& Jensen, 1977)

Individual characteristics and roles within the group

Salient characteristics of group members that have an impact on group.

Age, gender, ethnicity, culture, class, confidence, status with peers, additional needs etc. (Westergaard 2009)

Group 'roles' e.g. 'good listener' 'silent critic' 'monopoliser' (Vernelle 1994, cited in Westergaard, 2009).

\section{Yalom's factors}

The most relevant to adolescent group work:

Catharsis, Existential factors, Interpersonal learning, Group cohesiveness, Universality (Yalom 1970, cited in Corder, Whiteside \& Hazlip, 1981).

\section{Considerations of adolescence}

The 'normative crisis' self consciousness, fitting in (Malekoff 2004).

Separation/individuation, identity formation, intimacy/isolation (Erikson 1980). 


\section{Example of initial coding}

Improvisation 2: 'Spanish'

The Spanish theme is apparent throughout the improvisation] Two guitars keep a Comment [Y1] : \$TRUSTURE; keep to driven rhythmic pace. Maracas and egg shakers keep time and embellish the piece Givens, metches theme. with extended shakes. SSome initial pushing of pace is quickly resolved and the group 'falls in' $\mid$ | play rising and falling melodic lines on the flute, which gives deffitition to the group's phrasing and centres the tonality strongly on e minor. A significant change comes after $2 \mathrm{~min} 40$, when I put down the flute and pick up a tambourine. This change is met with a number of other group members also switching instruments or initiatiating new musical ideas. For example, a guitar player initiates new chord choices, another group member picks up a kalimba, and the maracca player shakes in long extended shimmers rather than keeping the beat II repeat a rhythm on the tambourine, despite this the group feels through this part of the improvisation like it lacks a solid foundation]. The group comes together again very near the end decrescendoing and funishing naturally.)

Again, we listen back to the improvisation. I point out the changes I hear throughout it. Some of the group members make comments about each other's playing - "that's a cool rhythm, was that you?" I ask the group which improvisation they feel they were more 'together' in. They say they sounded more together in the first one, but that they took more musical risks in the second.

\section{Examples of later process}

Musical indications of trust and comfort was initially defined as: "elements of music that indicate a level of risk taking or conversely the seeking of safety".

This was placed into a category interpersonal factors, which was defined as: "how group members relate to each other (including staff and therapist)".

The idea of cohesion became prominent in the coding of the data and this was added as a category. 
Fohesion was then sorted under interpersonal factors and re-named negotiating your place.

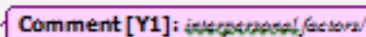

A number of other themes which related to interpersonal factors became apparent. I also realized that the definition I had given interpersonal factors (how group members relate to each other) was an overarching idea for all of the themes and essentially synonymous with 'group dynamics'. Interpersonal factors was re-named connection and defined as 'the quality of and insight into relationships between group members".

(Negotiating your place was re-named belonging) This was labeled: "describes a sense of whole group cohesion or 'we-ness' and how individual group members negotiated their place in this".

Comment [Y2]: Negotiating o place in the group about trying to belong in it? or meybe about trying to prove you dont

All the pieces sorted under musical indications of trust \& comfort had to do with active connections being made between group members. The theme was re-named musical indications of connection, trust and comfort and re-defined as: "the qual ity of musical connections between group members."

Musical indications of connection, trust and comfort was a prominent theme in the data. I felt it important to give it its own heading even though the musical data simply illustrated levels of belonging and connection.

Some pieces of data were sorted into new or different themes and categories. For example, the piece relating to comment $\mathrm{Y} 3$ began in therapist role but was moved to structure, and later placed with other data that related specifically to musical structure.

Comment [Y3]: Therepist role is importent throughout... perheps this nesds

The writing process saw further refining of theme and category definitions, which were eventually stated as the key point from that group of data.

to be absolved into an ides running through all the other themes rether than a seperate ides. A lot of deta reistes to lesdership stum by other group members too - perheps this shouldn't be $s 0$ separete. 


\section{APPENDIX FOUR}

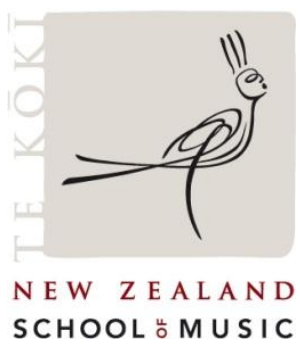

MUSIC THERAPY PROGRAMME (MMUSTher)

Research Title: Establishing an understanding of group process within single-session music therapy groups open to both adolescents and mental health staff.

\section{Information Sheet for young people}

Dear.

As you know, I am a music therapy student doing a placement at this unit. As part of my study, I need to write an essay about some of my work here at $* * * * *$. I am really interested in what happens in groups, so I have chosen to write about some of the things we do in group music therapy and some of the music we make. If you agree, I will listen back to recordings made in the groups and write about them.

In my essay, I won't be writing directly about you, but I might need to refer to the specific ways that people respond to music, and to other group members. For example I might need to mention that 'one of the group members was very skilled at guitar' or 'one of the group members found it difficult to concentrate'. I won't include your name.

I need to talk to my examiners, lecturers and classmates about the essay and they will ask me some questions. If you give your permission, they might listen to some of our recordings too. I will edit the recordings so they won't include your name, or your voice. No-one else will hear the recordings.

Once I have finished the essay, I will give the unit a summary of it. If I write about the group you were in, and you would like, I will give you a copy too. If I write it extremely well, the essay could be published in an academic journal with some help from my lecturer.

I only need to talk to my lecturers and classmates about one group, so it may not be the group that you were in. If you don't want me to write or talk about the group you were in, or use the recordings, that's completely fine, and it won't change anything we do together at ${ }^{* * * *}$. If you give consent but then you change your mind, that's fine too, there are lots of other group sessions I could use.

If you have any questions you can talk to me or Sally.

Yours sincerely, 


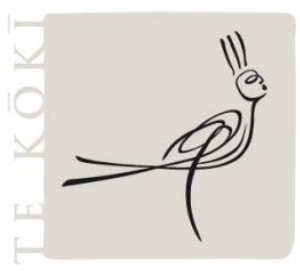

N E W Z E A L A N D SCHOOL

\section{MUSIC THERAPY PROGRAMME (MMusTher)}

\section{Research Title: Establishing an understanding of group process within single-session music therapy groups open to both adolescents and mental health staff.}

\section{Consent Form for young people}

I have read the information sheet. Yes/No

I have had the opportunity to discuss this information, and know I can ask questions at any time. Yes/No

I , .................................. (name) give consent for Erin to write about the music therapy group I participated in. $\quad$ Yes/No

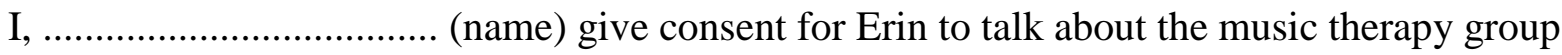
I participated in, with her examiners, lecturers, and classmates. Yes/No

I, .................................. (name) give consent for Erin to share audio recordings from the music therapy group I participated in, with her examiners, lecturers, and classmates. Yes/No

Consent may be withdrawn by contacting my supervisor Daphne Rickson at 6448015799 x 6979.

Signed.

Print Name

Date. 


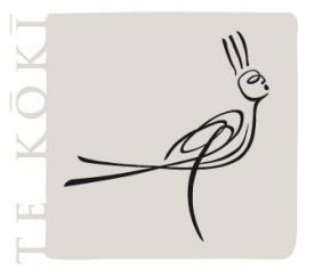

NEW Z E ALAND

SCHOOL

MUSIC THERAPY PROGRAMME (MMusTher)

\title{
Research Title: Establishing an understanding of group process within single-session music therapy groups open to both adolescents and mental health staff.
}

\author{
Information sheet for staff who participated in a group music therapy session
}

Dear.

As you know, I am a music therapy student doing a placement at the **** unit. As part of my study, I need to write a dissertation about an aspect of my work here at ****. I am really interested in group process and dynamics, so I have chosen to write about the group music therapy sessions I take. The purpose of my research is to improve my learning and to inform other music therapy students, practitioners and carers of particular issues involved in the work.

My research will involve looking back over the clinical notes I take following sessions, rereading my own reflective journal entries, and listening again to audio recordings from the group. Keeping a reflective journal is a normal part of music therapy practise, and is a way to document personal reflections and critical thinking. It is also normal to take audio recordings within sessions, when clients agree. This research process, only looking back over data that would be taken anyway as part of normal practise, aims to minimise any risks there would be to group participants.

Through looking back over these sources of information, I hope to gain new insights into my own music therapy practise, and to develop ideas about group process in single music therapy sessions. I hope these ideas might be relevant to other music therapists and staff working in one-off groups or groups that constantly change.

I need to include a case vignette from my practise, which will be a description of one group in particular. I also need to present this case to my examiners, lecturers and classmates, who will discuss it with me and ask me further questions. I may play them audio recordings of music from this group to illustrate the points we discuss. I will edit any recordings so they do not include the names or voices of any of the $* * * *$ or staff who participated. This is to protect their confidentiality.

I won't be writing directly about any of the young people or staff involved in the group, but I might need to refer to the specific ways that people respond to music, and to other group members. For example I might need to mention that 'one of the group members was very 
skilled at guitar' or 'one of the group members found it difficult to concentrate because of their illness'. I will not include any real names, or any information that would identify group participants to someone outside of $* * * *$.

I will provide a summary of my research to the $* * * *$ unit, and if they wish, to staff and young people included in the vignette. If my work is of appropriate quality, some of it may be published in an academic journal in collaboration with my research supervisor, Daphne Rickson.

I am writing to express my interest in describing a group in which you participated, for the case vignette. I only need to include one case vignette, so it may not ultimately be about the group that you were in. If you decide not to give your consent, that is fine, there are many other groups I can write about. If you do give your consent and then decide to withdraw it, that is fine too. You can do this by contacting the Music Therapy Programme Leader at 644 $8015799 \times 6410$.

If you have any questions or wish to discuss this further, you are welcome to contact me or my research supervisor:

Dr Daphne Rickson, Senior Lecturer (Music Therapy), New Zealand School of Music, Ph: 048015799 x6979 or email: d.rickson@massey.ac.nz

Yours sincerely,

\section{Erin Upjohn Beatson}

Email: tikitikitembo@gmail.com

Ph. 0276342046 


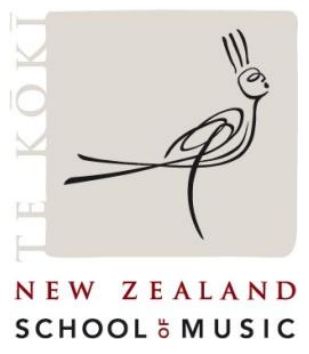

MUSIC THERAPY PROGRAMME (MMusTher)

\section{Research Title: Establishing an understanding of group process within single-session music therapy groups open to both adolescents and mental health staff.}

\section{Consent form for staff who participated in a group music therapy session}

I have read the information sheet. Yes/No

I have had the opportunity to discuss this information, and know I can ask further questions at any time. Yes/No

$\mathrm{I}$, (name) give consent for the music therapy group I participated in to be described in a 'case vignette', for the above research project. Yes/No

$\mathrm{I}$, (name) give consent for the music therapy group I participated in to be discussed with examiners, lecturers, and students of the music therapy programme at the New Zealand School of Music. Yes/No

$\mathrm{I}$, (name) give consent for audio recordings from the music therapy group I participated in, to be shared with examiners, lecturers, and students of the music therapy programme at the New Zealand School of Music. Yes/No

Consent may be withdrawn by contacting my supervisor Daphne Rickson at 6448015799 x 6979.

Signed.

Print Name.

Date. 


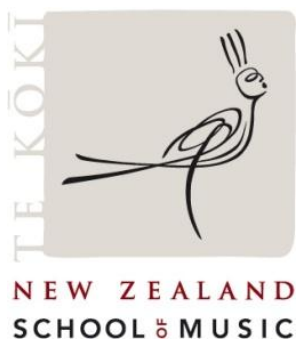

MUSIC THERAPY PROGRAMME (MMusTher)

\title{
Research Title: Establishing an understanding of group process within single-session music therapy groups open to both adolescents and mental health staff.
}

\author{
Information Sheet for staff carers, giving consent on behalf of a young person
}

Dear.

As you know, I am a music therapy student doing a placement at the **** unit. As part of my study, I need to write a dissertation about an aspect of my work here at ****. I am really interested in group process and dynamics, so I have chosen to write about the group music therapy sessions I take. The purpose of my research is to improve my learning and to inform other music therapy students, practitioners and carers of particular issues involved in the work.

My research will involve looking back over the clinical notes I take following sessions, rereading my own reflective journal entries, and listening again to audio recordings from the group. Keeping a reflective journal is a normal part of music therapy practise, and is a way to document personal reflections and critical thinking. It is also normal to take audio recordings within sessions, when clients agree. This research process, only looking back over data that would be taken anyway as part of normal practise, aims to minimise any risks there would be to group participants.

Through looking back over these sources of information, I hope to gain new insights into my own music therapy practise, and to develop ideas about group process in single music therapy sessions. I hope these ideas might be relevant to other music therapists and staff working in one-off groups or groups that constantly change.

I need to include a case vignette from my practise, which will be a description of one group in particular. I also need to present this case to my examiners, lecturers and classmates, who will discuss it with me and ask further questions. I may play them audio recordings of music from this group to illustrate the points we discuss. I will edit any recordings so they do not include the names or voices of any of the young people or staff who participated. This is to protect their confidentiality.

I won't be writing directly about any of the young people or staff involved in the group, but I might need to refer to the specific ways that people respond to music, and to other group members. For example I might need to mention that 'one of the group members was very skilled at guitar' or 'one of the group members found it difficult to concentrate because of 
their illness'. I will not include any real names, or any information that would identify group participants to someone outside of $* * * *$.

I will provide a summary of my research to the $* * * *$ unit, and if they wish, to staff and young people included in the vignette. If my work is of appropriate quality, some of it may be published in an academic journal in collaboration with my research supervisor, Daphne Rickson.

I am writing to express my interest in describing a group in which

one of the young people you care for participated. I am writing to you as someone involved in their daily care during their time at the $* * * *$ unit. I will make an effort to ascertain whether the young person assents to this, but due to their current illness and the brevity of their engagement with group music therapy, it may not be appropriate to explain all details and have them sign consent forms.

I only need to include one case vignette, so it may not ultimately be about the group they were in. If you decide not to give your consent, that is fine, there are many other groups I can write about. If you do give your consent and then decide to withdraw it, that is fine too. You can do this by contacting the Music therapy Programme Leader at 6448015799 x 6410.

If you have any questions or wish to discuss this further, you are welcome to contact me or my research supervisor:

Dr Daphne Rickson, Senior Lecturer (Music Therapy), New Zealand School of Music, Ph: 048015799 x6979 or email: d.rickson@massey.ac.nz

Yours sincerely,

\author{
Erin Upjohn Beatson
}

Email: tikitikitembo@gmail.com

Ph. 0276342046

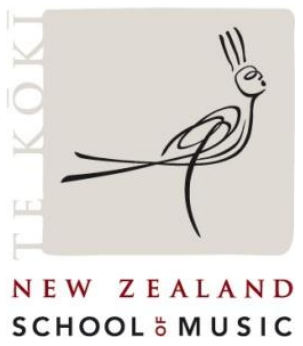

MUSIC THERAPY PROGRAMME (MMusTher) 


\section{Research Title: Establishing an understanding of group process within single-session music therapy groups open to both adolescents and mental health staff.}

\section{Consent form for staff carers, giving consent on behalf of a young person or colleague}

I have read the information sheet. Yes/No

I have had the opportunity to discuss this information, and know I can ask further questions at any time. Yes/No

I, (name) give consent for the music therapy group (name) participated in to be described in a 'case vignette', for the above research project. Yes/No

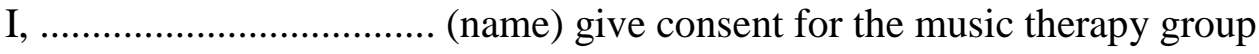
(name) participated in to be discussed with examiners, lecturers, and students of the music therapy programme at the New Zealand School of Music. Yes/No I, . (name) give consent for audio recordings from the music therapy group (name) participated in, to be shared with examiners, lecturers, and students of the music therapy programme at the New Zealand School of Music.

Yes/No

Consent may be withdrawn by contacting my supervisor Daphne Rickson at 6448015799 x 6979.

Signed.

Print Name

Date. 


\section{APPENDIX FIVE}

\section{Key ideas on group process}

- Beginning and ending with undemanding, structured activities helped to create a comfortable and safe space.

- Staff, like adolescent group members, were affected by self-consciousness at times. They appeared to become more comfortable as a session continued.

- Participation improved when expectations were clear.

- Adolescents appreciated stability in the music. Musical stability and 'fullness' were important for establishing cohesion.

- Those that were familiar with the environment and therefore knew what to expect, were more forthcoming in the groups. They were also more likely to test boundaries and to challenge (or demand for) leadership.

- When the group had higher energy, individuals were more likely to assert their preferences. Likewise, when group members took on more autonomy, this brought energy to the group.

- Some groups became more autonomous throughout a session.

- Groups that improvised together went through a developmental process in the music, moving from disconnection from each others' playing, to establishing common ground, to cohesion, to risk-taking. Session closure was also negotiated through one improvisation.

- Playing music that was structured, comfortable, safe, and 'in time' allowed some groups to find common ground.

- Sounding chaotic did not always indicate a lack of cohesion. Group members took risks such as changing instruments or playing against the beat, but were able to decrescendo together and come to a natural ending.

- When a group heard themselves playing successfully together, this reinforced their sense of being a group.

- Positive feedback between peers strengthened trust.

- Group members only made meaningful verbal comments once they had reached a level of comfort and trust in each other. 
- When an individual left the session, this could cause energy to drop. The effect on the remaining group depended on how integrated the leaving person had been.

- When a new member joined a session, this could be disruptive to the 'flow' of the session. Instructions had to be repeated, and other group members reverted to playing with little connection to each other. The effect on the group depended on how comfortable the new member was in the environment, and so how easily they were able to slot in. 


\section{Recommendations to group leaders}

- Choose and prepare a therapy space which is large enough to allow for movement and for people to be away from each other, while still encouraging closeness.

- Have more than one staff member in a group where possible. This is extremely helpful when dealing with unexpected situations.

- Consider beginning and ending the group with structured and undemanding activities.

- Give clear instructions and do not change these in the middle of an activity.

- Minimise silences in the groups by being highly prepared and ready to move on to the next activity.

- Promote safety and comfort in the group by initially avoiding emotionally challenging tasks and using music that is likely to be 'comfortable'.

- Proceed with care for the whole group's safety when addressing difficult topics.

- Provide musical structure for the group to lean on and play off. This musical structure can be very simple.

- Take a firmly directive role to include any members excluded by the group.

- Constantly clarify expectations throughout the session especially when new members join.

- Even when meeting spontaneously, consider briefly clarifying the purpose of the session so that shared expectations can be established.

- Be aware that sustaining a rigid structure for too long could work against the group.

- Encourage autonomy by being aware of what leadership roles could be taken by others in the group.

- Make use of all group members' skills and interests where these are known.

- Be ready to fluidly move between leadership styles. Some group members will respond to more structure, others to more freedom.

- When improvising, support the group members to listen to each others' playing. Consider placing a procedural structure around who will begin, followed by whom. Weave connections between group members' music and highlight any commonalities between them. When one person's music is overpowered by others, synchronise with their playing to support them to be heard.

- Make opportunities for the group to hear themselves and to reflect on this. 
- Keep an accepting stance which avoids pressure or drawing attention to individual group members. Allow new group members the space to listen and observe. 